\title{
Climatology and Landfall of Tropical Cyclones in the South- West Indian Ocean
}

\author{
Alberto F.Mavume', Lars Rydberg ${ }^{2}$, Mathieu Rouault ${ }^{3}$ and Johann R.E. Lutjeharms ${ }^{4}$ \\ ${ }^{1}$ Universidade Eduardo Mondlane, Faculdade de Ciências, Departamento de Física, PO Box 257, Maputo, \\ Mozambique; ${ }^{2}$ University of Gothenburg, Department of Earth Sciences, Oceanography, Box 460, SE-405 \\ 30 Gothenburg, Sweden; ${ }^{3}$ Department of Oceanography, University of Cape Town, 7700 Rondebosch, South \\ Africa; ${ }^{4}$ Department of Oceanography, University of Cape Town, 7700 Rondebosch, South Africa
}

Keywords: Tropical cyclones, Indian Ocean, Mozambique Channel, global change, sea surface temperatures, ENSO, landfall

\begin{abstract}
The climatology of cyclone formation and behaviour in the South-West Indian Ocean, including landfall in Mozambique and Madagascar, has been investigated. The records used were obtained by merging track data from the Joint Typhoon Warning Centre with data from La Reunion - Regional Specialised Meteorological Centre. During the period 1980-2007, 12.5 cyclones per year were formed; $85 \%$ of which in November-April (the cyclone season). The number of intense tropical cyclones increased from 36 during 1980-1993 to 56 during 1994-2007, parallel to a simultaneous but smaller decrease in the number of tropical storms. This increase in intense tropical cyclones occurred at the same time as an increase in the mean sea surface temperature of $0.12^{\circ} \mathrm{C}$. This temperature increase seems insufficient to explain the increased activity. In addition, investigating a longer record (1952-2007) from the same sources indicates a long-term decrease in cyclone frequency as well as in landfall, although this was simultaneous with a substantial increase (about $0.3^{\circ} \mathrm{C}$ ) in sea surface temperature. However, it is recognised that records before 1980 suffer from too few wind intensity data. From 1980-2007, the number of land-falling cyclones was 64 (compared to 88 from 1952-1979), 16 of which came ashore in Mozambique and 48 in Madagascar. Seasonal variations in areas of genesis and preferred tracks are presented and discussed in relation to a number of indices. Minimum and mean sea surface temperatures for cyclone genesis are also estimated.
\end{abstract}

\section{INTRODUCTION}

\section{Cyclone identification and intensity}

Tropical cyclones form in equatorial regions, where sea surface temperatures (SSTs) exceed 26$27^{\circ} \mathrm{C}$ (Palmén, 1948; McBride, 1995), but rarely within less than $4^{\circ}-5^{\circ}$ from the Equator (Anthes, 1982). Henderson-Sellers et al. (1998) have listed several other conditions favouring genesis, such as (i) large values of low level relative vorticity, (ii) weak vertical and horizontal wind shear, (iii) conditional instability through a deep atmospheric layer, (iv) large relative humidity in the lower and middle troposphere, all of which are fulfilled within the Inter-Tropical Convergence Zone (ITCZ), and (v) a deep oceanic mixed layer.

Fink and Speth (1998) have studied cyclone genesis region-wise, using data from 1968-1997. They found that most cyclones of Maximum Sustained Wind (1-min MSW) exceeding $17 \mathrm{~ms}^{-1}$ are formed in the North-West Pacific (27 out of a total of 86 per annum). In that region, cyclones are relatively frequent throughout the year, with four cyclones reaching "super-typhoon intensity" 
$\left(\mathrm{MSW}>69 \mathrm{~ms}^{-1}\right)$. In the South-West Indian Ocean (SWIO), cyclones are generated mainly between November and April, with an average of 12 per year. Gray (1975) has investigated the period 19521971, reporting a global average of 80 cyclones per year. However, data before the satellite era must be regarded as relatively unreliable. Not until the Dvorak technique was fully introduced in the 1980s, (although applicable from 1968 onwards ; see http://www.aoml.noaa.gov/hrd/tcfaq/H1.html; Dvorak, 1984) could data on MSW and cyclone tracks be regarded reliable for detailed statistics. This should be particularly true for more remote cyclone regions such as the SWIO, where ground truth data and reconnaissance flights are rare.

\section{Cyclone activity in relation to the changing global environment}

Cyclone activity, i.e. frequency and intensity (MSW), may depend on natural cycles such as the El Niño-Southern Oscillation (ENSO) according to Pielke and Landsea (1999), the Quasi-Biennial zonal wind Oscillation (QBO) as reported by Landsea et al. (1999) and the Madden-Julian Oscillation (MJO) as described by Madden and Julian (1994). El Niño is known to cause increased cyclone activity in the South and in the North-East Pacific, but decreased activity in the North Atlantic and in the North-West Pacific (Landsea, 2007), as expected with regard to the deviations in SSTs. An east phase QBO seems to reduce activity in the North Atlantic (Gray, 1984). The MJO has been associated with higher frequency in the Pacific (Sobel and Maloney, 2000).

Trends in cyclone frequency and intensity have been studied by several authors (i.e. Emanuel, 2005a; Trenberth, 2005; Webster et al., 2005). Emanuel, for example, has emphasized a substantial increase in the intensity over the past 50 years and Webster et al. have found an almost $100 \%$ increase in the number of the most intense cyclones (MSW>59 $\mathrm{ms}^{-1}$ ), using data from 1974-2005. However, there are some doubts concerning the quality of the longer series, particularly concerning intensity (Landsea, 2007; Knapp and Kossin, 2007). Some authors underline the uncertainties, claiming that a link between increasing intensity and higher
SSTs cannot be shown (e.g. Pielke, 2005; Landsea et al., 2006) and others emphasize that increasing SSTs feed more intense cyclones (e.g. Emanuel, 2005b; Webster et al., 2005; Holland and Webster, 2007). Webster et al. (2005) have also referred to deMaria and Kaplan (1994) who have indicated, in a study from the North Atlantic, that there is a correlation between the SSTs on one hand, and the occurrence and intensity of cyclones on the other.

\section{Cyclone activity in the SWIO}

The climatology of SWIO cyclones has been investigated in a number of studies, i.e. by $\mathrm{Xu}$ (1992), Jury (1993), Xie et al. (2002), Zhang et al. (2004) and Ho et al. (2006). Jury has reported increased frequency in cyclone formation during the east phase of QBO, when upper level westerlies are weakened. El Niño years have lower frequencies, as explained by increased subtropical upper-level westerlies. Ho et al. (2006) have indicated that El Niño years are simultaneous with increased frequency/genesis of tropical cyclones west of $75^{\circ} \mathrm{E}$, but decreases east of $75^{\circ} \mathrm{E}$, all this vice versa during La Niña. The largest cyclone activity was found in phase 2-4 of the MJO (about 10 cyclones in 100 days), while there is lower activity during other phases. Ho et al., 2006) have used the series from JTWC (Joint Typhoon Warning Centre) for the years 1979-2004, but have included a comparison with the LR-RSMC (La Reunion - Regional Specialised Meteorological Centre) record, as shown in Figure 1. Kuleshov and de Hoedt (2003) have found an increased cyclone frequency between $85-105^{\circ} \mathrm{E}$ during La Niña years compared to El Niño. Bessafi and Wheeler (2006) have in turn found significantly increased frequency of tropical cyclone formation during the active phase of MJO.

Vitart et al. (2003) studied landfall over Mozambique using observations and model integrations. They have employed a cyclone record from Neumann (1993), the zonal wind from the National Centers for Enviromental Prediction (NCEP) reanalysis and SSTs (Kalnay et al., 1996) to identify predictors and potential physical mechanisms responsible for landfall. According to Vitart et al. (2003), a coupled Global Circulation Model with high horizontal resolution is capable 
of predicting landfalls. Landfall is more common during La Niña years, simultaneous with a negative zonal mean flow (averaged for 850-200 hPa). El Niño years have fewer landfalls and a positive zonal mean flow. Landman et al. (2005) have tested a regional model with the aim to examine its ability to reproduce landfall areas and cyclone tracks. Their results indicate that the regional model is able to simulate cyclone-like vortex tracks across Madagascar and into the Mozambique Channel.

The present study examines tropical cyclone climatology of the SWIO (west of $100^{\circ} \mathrm{E}$ ) based on a merged data set to achieve the maximum coverage. The study period covers 56 cyclone seasons, from 1952-2007. The occurrence, frequency and landfall of tropical cyclones during this period, as well as the more detailed climatology, including seasonal variations in formation areas, in preferred tracks and in intensity (1-min MSW), were investigated using data from 1980-2007. Specifically, the changes in frequency and intensity of cyclones in relation to global warming and increasing SSTs are addressed, for the accurate determination of areas of formation and intensification. Genesis and occurrence in relation to ENSO and other climate indices have also been investigated.

\section{DATA AND METHODS}

One single cyclone record was constructed by merging track data from LR-RSMC (http://www. meteo.fr/temps) and JTWC (http://www.npmoc. navy.mil/jtwc.html). This procedure takes JTWC as the basic sample, since it has the longest record available and in addition provides access to updated TC track position errors. The LR-RSMC dataset, which is not fully updated, has been used to fill in gaps encountered within JTWC data. The period chosen was 1952-2007, starting from the season 1951/52 and ending with the season 2006/07. Cyclones appearing outside the cyclone season (defined as November to April) have been excluded from this analysis. These were $15 \%$ of the total (see also Figure 1). A cyclone is considered outside the season if the majority of its days are outside the season. The area of the SWIO is defined as $0^{\circ}-40^{\circ} \mathrm{S} ; 30^{\circ}-100^{\circ} \mathrm{E}$. All cyclones reaching storm intensity (1-min MSW>17 $\mathrm{ms}^{-1}$ ) have been grouped according to the Saffir-Simpson scale (Saffir, 1974; Simpson and Riehl, 1981), in six categories; with tropical storms (TS) in the range from $17<\mathrm{MSW}<33$ $\mathrm{ms}^{-1}$ and then five categories of tropical cyclones;

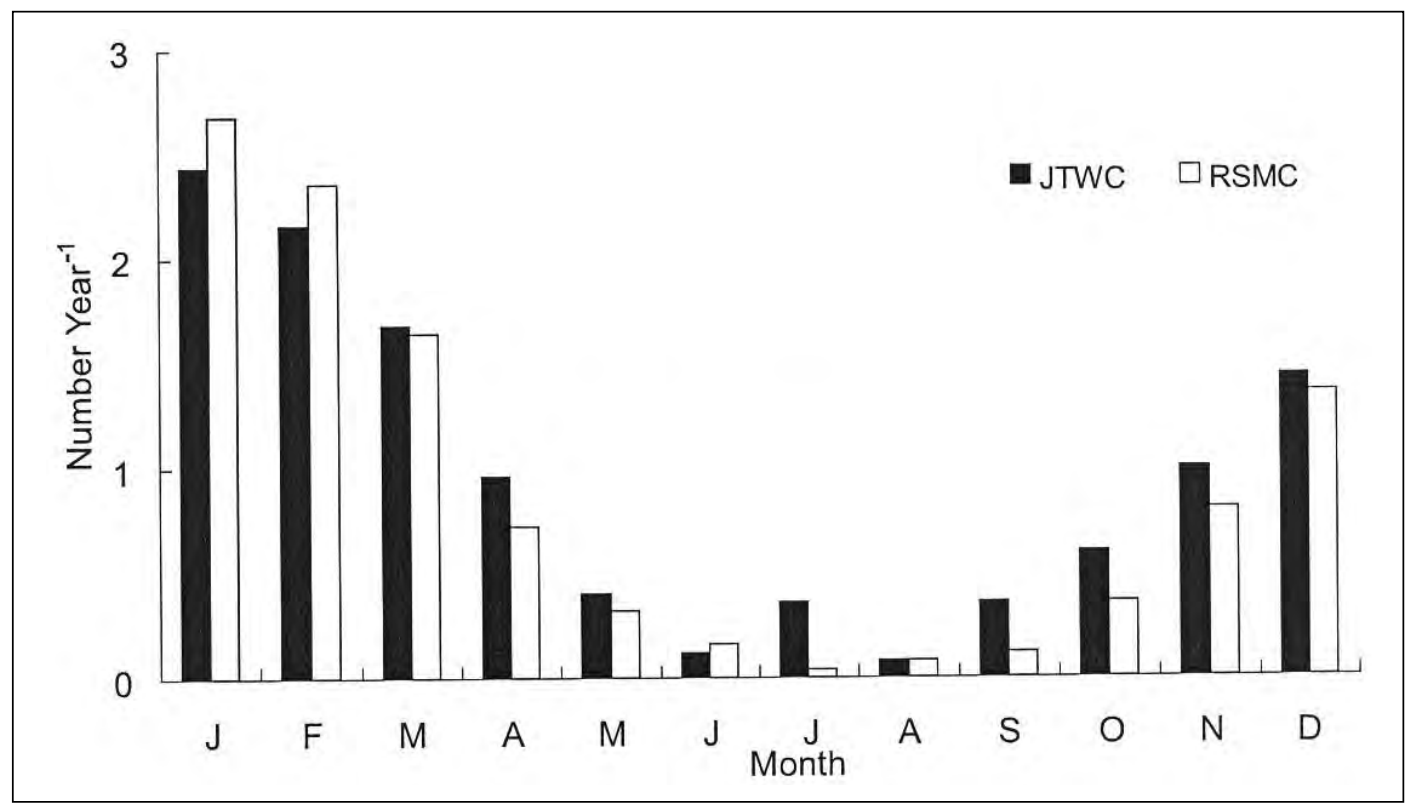

Fig. 1. Monthly mean number of cyclones $\left(M S W>17 \mathrm{~ms}^{-1}\right)$ formed in the South Indian Ocean (1979-2004); a comparison between the two sets of records from Ho et al. (2006) as discussed in text. This figure does not take into account that the records are using different definitions of MSW 
category 1 with MSW between 33-42 $\mathrm{ms}^{-1}$, category 2 between $43-49 \mathrm{~ms}^{-1}$, category 3 between $50-58$ $\mathrm{ms}^{-1}$, category 4 between $59-68 \mathrm{~ms}^{-1}$, and category 5 with MSW $>69 \mathrm{~ms}^{-1}$. Thus, the word "cyclone" in this text means that all TSs and TCs are included.

A full inspection of all cyclone data in both records has been performed, and differences in the definitions of MSW have been levelled to JTWC MSW. The JTWC had fewer missing values, both for tracks (positions) and MSWs. However, before 1979 there are many missing values. Some cyclones completely escaped notice in one or the other record. This is readily seen from Figure 2, showing all MSW data for the periods 1952-1979 and 1980-2007, respectively. Thus, the number of cyclones as such (which for example assumes exclusion of low wind cyclones, with 1-min MSW $<17 \mathrm{~ms}^{-1}$ ) is also uncertain. Therefore the present study has concentrated on the series from 1980-
2007, for which data are definitely more consistent and reliable.

Original data do not contain a full record of cyclones by landfall location. Thus, a separate database for land-falling cyclones, including time, position, MSW and also Mean Sea Level Pressure (MSLP) in Mozambique and Madagascar has also been produced. Landfall locations and times were defined following Emanuel (2003). It is assumed that landfall occurs when a part of the eye-wall passes directly over the coast or an adjacent barrier island (landfall on islands away from the coast were not included). Some tropical cyclones make multiple landfalls. Only landfall at the first point of occurrence has been accounted for. Further data treatment is explained in the results section.

Trends in cyclone and SST development and their statistical significance have been assessed using linear regression analysis and t-test (Cardillo,
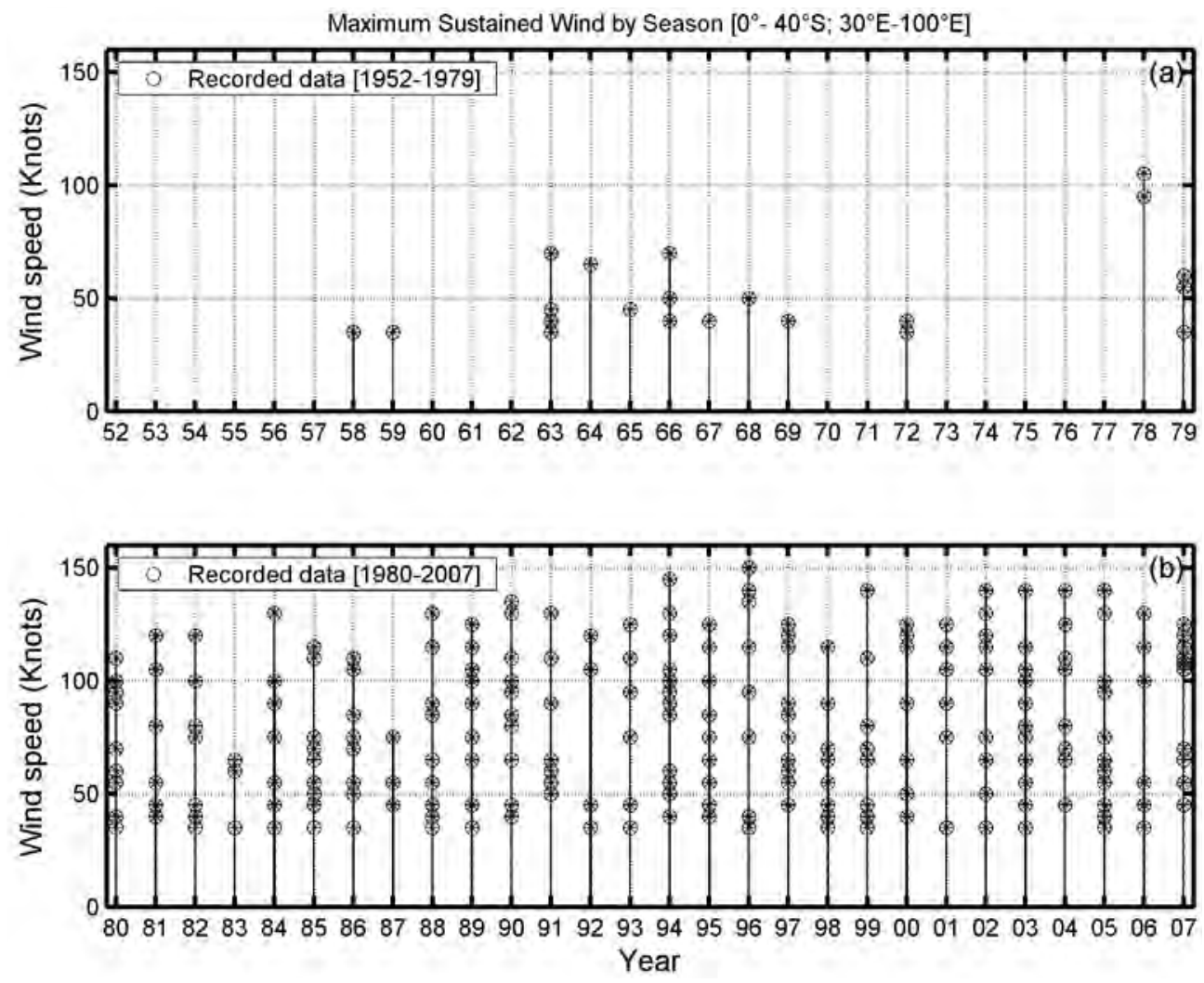

Fig. 2. Maximum Sustained Wind (1-min, in knots) for all SWIO cyclones (November - April); upper panel (a) from 1952-1979, lower panel (b) for 1980-2007 
2007). Then, the statistical significance has been verified by the non-parametric Mann-Kendall test (Yue et al. 2002). It has been noted that this test gives only the significance and directions of the trend but not the trend itself, thus the non-parametric Sen's slope estimator (Sen, 1968) has been employed to verify the trend obtained by linear regression. Like the Mann-Kendall test, Sen's slope estimator can be applied to data that do not come from a normal distribution and is not affected by outliers.

\section{RESULTS}

The results section deals first with inter-annual variability and trends in cyclone activity (frequency and intensity). Then, relationships between activity (inter-annual and seasonal), and genesis areas on one hand, and variations in SSTs and ENSO on the other, are analysed. We discuss the importance of SSTs and mixed layer heat content for boosting cyclone activity. Land-falling cyclones are dealt with separately. Activity and genesis in the Mozambique Channel (MC), which has higher
SSTs and weaker winds than the open SWIO, are presented separately.

\section{Number of cyclones, trends, cyclone intensity and its seasonal distribution}

Cyclone frequency in the SWIO and the MC $\left(10^{\circ}-\right.$ $27^{\circ} \mathrm{S} ; 30^{\circ}-50^{\circ} \mathrm{E}$ ), back to 1952 , is given in Figure 3. Rather surprising, both series indicate a decrease in cyclone frequency, if data back to the 1960s and 1950s are considered. Comparing the earlier record (1952-1979) with the more recent one (1980-2007) there is evidence of a decrease over the SWIO from 330 to 303 and over the MC from 97 to 56. However, because data before 1980 include several uncertainties, not much attention will be devoted to the full record. In the forthcoming analyses, only the record from 1980-2007 is considered, omitting another 10 out of 303 cyclones, because of missing track data.

Table 1 presents the total number of cyclones and mean monthly cyclone frequency for the period 1980-2007, separated between the SWIO and the

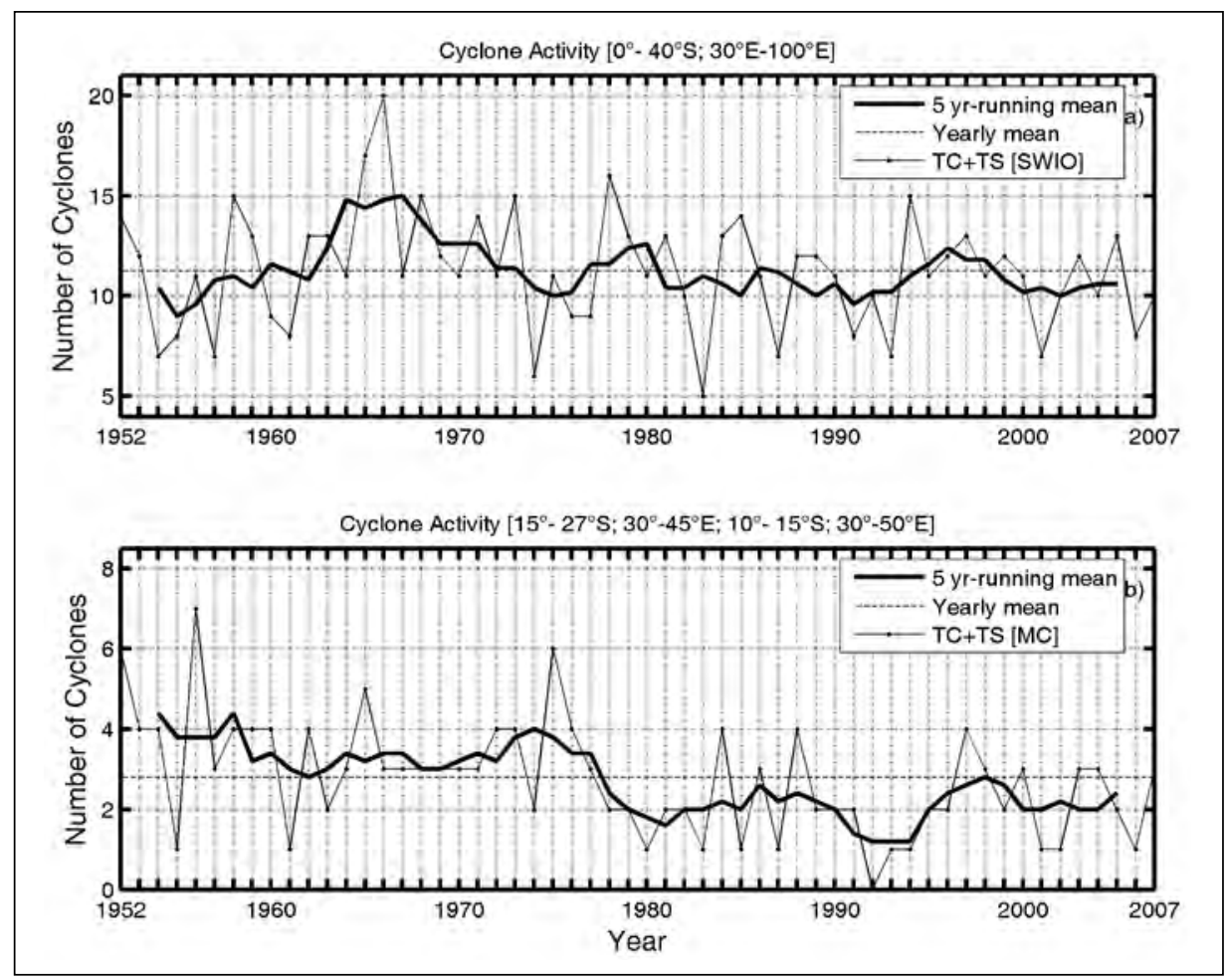

Fig. 3. Number of cyclones (TS+TC, November-April) year by year (1952-2007) in the SWIO (a) and in the MC (b), respectively, indicating 5-y running mean and overall average 
Table 1: Total number of cyclones and frequency month by month (November-April) in the SWIO and the MC (1980-2007)

\begin{tabular}{lcccc}
\hline $\begin{array}{l}\text { Month } \\
\text { Number }\end{array}$ & $\begin{array}{c}\text { Mozambique Channel } \\
\text { All cyclones (TC+TS) }\end{array}$ & \multicolumn{2}{c}{$\begin{array}{c}\text { South-West Indian Ocean } \\
\text { All cyclones (TC+TS) }\end{array}$} \\
\hline November & 2 & 0.07 & Number & Frequency \\
December & 7 & 0.25 & 28 & 1.0 \\
January & 18 & 0.64 & 34 & 1.2 \\
February & 16 & 0.57 & 72 & 2.6 \\
March & 8 & 0.29 & 53 & 2.6 \\
April & 5 & 0.18 & 34 & 1.9 \\
Total & 56 & 2.0 & 293 & 10.5 \\
\hline
\end{tabular}

MC. Fifty percent of the cyclones in the SWIO and $60 \%$ of those in the MC appear in January and February. There is a minor preponderance of cyclones in March and April, compared to November and December. About 20\% (56 out of 293) occur in the MC (generated or entering). The number of cyclones per season is 10.5 in the SWIO and 2.0 in the MC. Given another $15 \%$ outside the season (i.e. Figure 1) and adding an estimated 10 cyclones from missing track data implies an annual mean frequency of $12.5 \mathrm{y}^{-1}$ in the SWIO and $2.3 \mathrm{y}^{-1}$ in the MC. Fink and Speth (1998), as mentioned, found a mean of $12 \mathrm{y}^{-1}$ for the period 1968-1997.

Figure 4 shows the total number of cyclones month by month, arranged by intensity, for a total of 293 cyclones; 118 being TSs and 175 TCs.

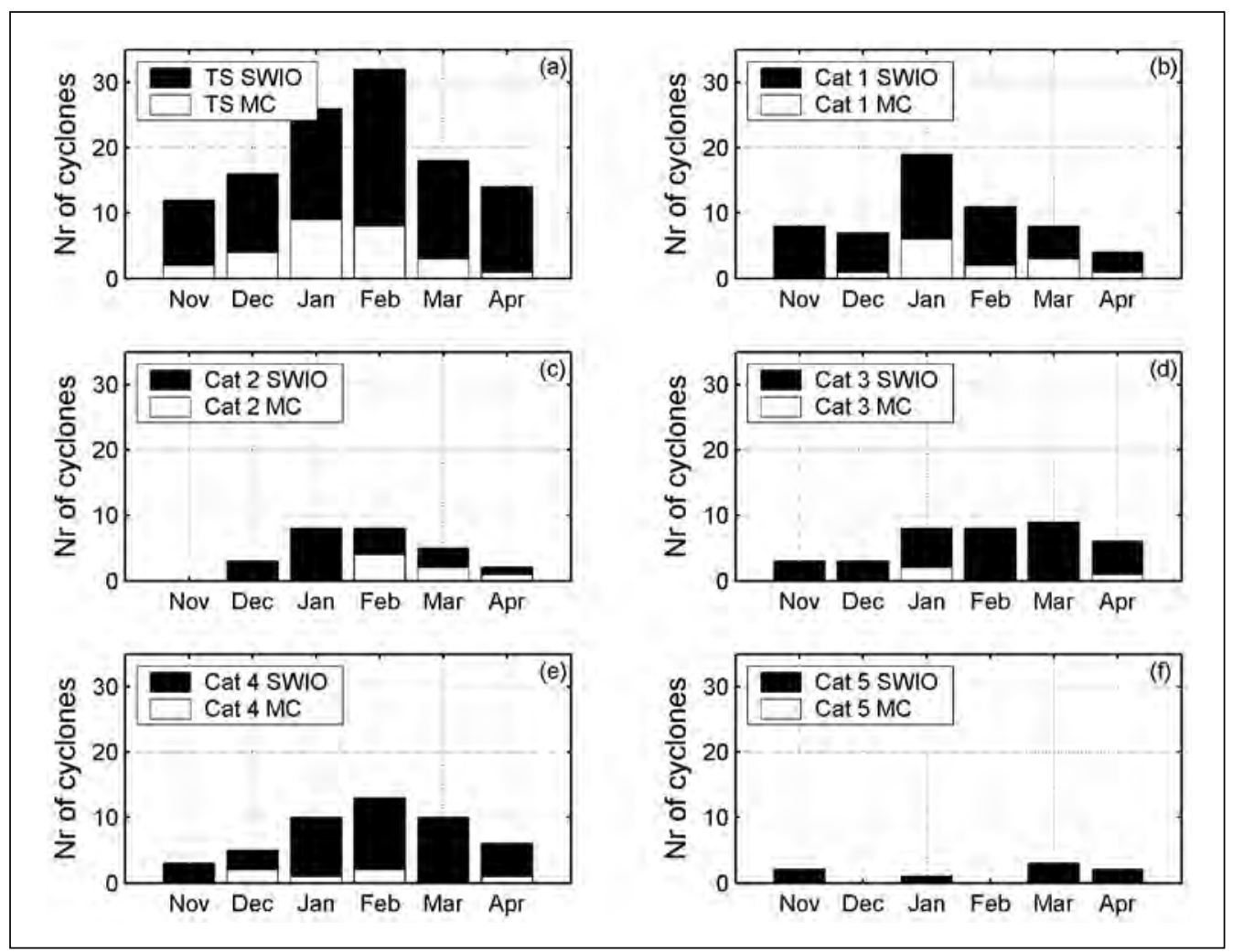

Fig. 4. Total number of cyclones in the SWIO and in the MC (1980-2007), month by month stratified by intensity, according to the Saffir-Simpson scale in tropical storms (TS, 4a) and five categories (Cat 1-5) of tropical cyclones (TC, 4b-f)) 
Scattered peaks are seen within all categories. These peaks seem random except for intense tropical cyclones (ITC), category 3-5. Intensive TCs are much more common from February-April than from November-January (57 compared to 34). Figure 4 also shows that ITCs are less common in the MC than in the SWIO as a whole $(<10 \%$ compared to $20 \%$ for all cyclones together).

\section{Cyclone activity (frequency and intensities), ENSO and SST dependence}

The number of cyclones per season is shown in Figure 5, with a distinction being made between TCs and TSs. The inter-annual variations are large, from 5-15, without any obvious correlation between TS and TC, with correlation coefficients of $\mathrm{TC} /(\mathrm{TC}+\mathrm{TS})=0.71, \mathrm{TS} /(\mathrm{TC}+\mathrm{TS})=0.49$ and TS$/$ $\mathrm{TC}=0.25$, respectively. The maximum number of cyclones (14-15) occurred in 1992, 1994 and 2005, all of which are La Niña years. The minimum number, five in 1983, occurred simultaneously with one of the strongest El Niño years. Still, a more rigorous analysis, using the Oceanic Niño Index (ONI) shows that ENSO alone does not explain the inter-annual variations.

Figure 6 shows the number of cyclone days, with distinction being made between TSs, less intense TCs (1-2) and ITCs (3-5). This figure clearly indicates the increasing number of ITCs, and also that this increase takes place mainly at the expense of fewer TCs (1-2). A minor increase in the total number of cyclone days (TS and TC combined) is also noted. The least-squares linear regression test has been performed here to evaluate trends in tropical cyclones of all categories. Trends are significantly different from zero at the 95\% confidence level for Category 3-5 (increase) and for TS (decrease), except for total activity. For Category 1-2 the significance is lower. The

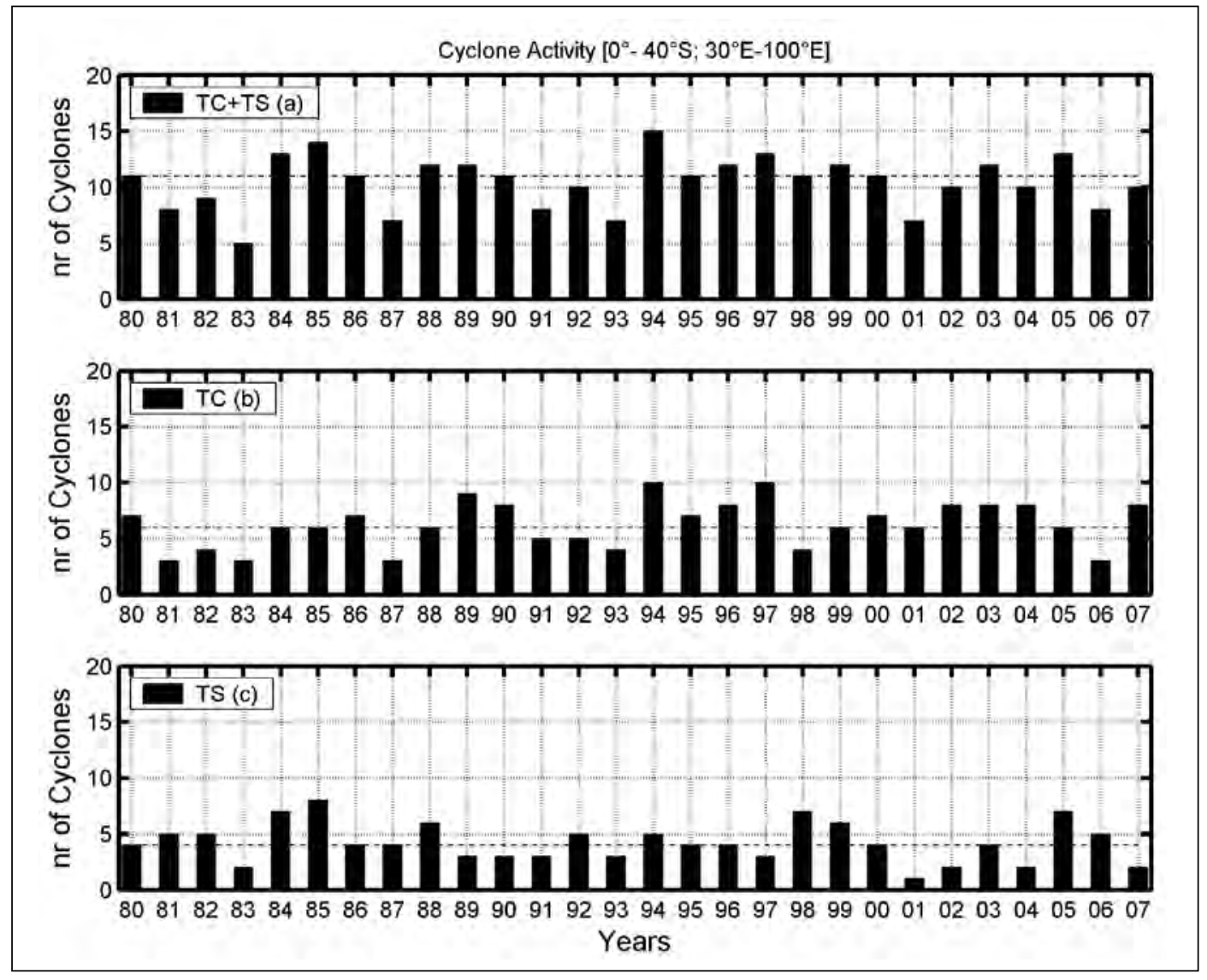

Fig. 5. Annual (November-April) number of cyclones in the SWIO, TC+TS, TC and TS, respectively 


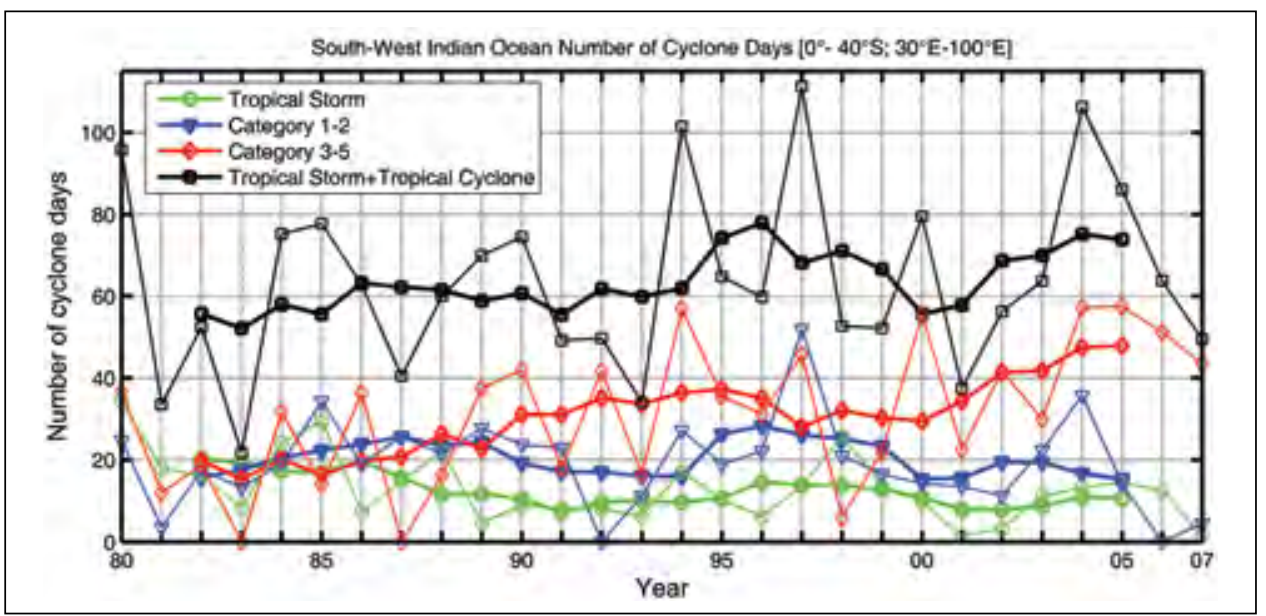

Fig. 6. Annual number of TS and TC days (Category 1-2 and Category 3-5) days in the SWIO. Tropical cyclones plus tropical storms (black curves), tropical cyclones (Category 3-5; red curves), tropical cyclones (Category 1-2; blue curves) and tropical storms (green curves). Thin-marked curves indicate the year-by-year variability, and the bold-marked curves show the 5-year running average

Man-Kendall test has been applied and verifies these results. The increase in ITCs is consistent with earlier work by Webster et al. (2005) who compared regional time series for 1970-2004 and also the recent work by Kuleshov et al. (2008). Given an average of 75 cyclone days per year, the mean lifetime of a cyclone is 7-8 days. However, the years of many TC days (or few) are the same as the years of many cyclones, so there is no apparent change in the lifetimes of cyclones.

Looking for variations in activity, Tables $2 \mathrm{a}$ and $2 \mathrm{~b}$ indicate co-variation between ENSO and cyclone frequency. Taking the high phase of ENSO (December-February), the total number of cyclones is 59 during El Niño years and 58 during La Niña (Table 2a). For the peak cyclone months (January-March, Table 2b) the numbers are 59 and 68 , respectively, thus with a slightly higher activity during La Niña years. It has been noted (Vitart et al. 2003; Reason and Keibel 2004 and Klinman and Reason, 2008) a tendency for landfall of extreme cyclones during La Niña years which increases the potential for infrastructure damage and lost of life during landfall over Mozambique and Madagascar.

Table 2a: Number of cyclones in the SWIO during ENSO high phase (December-February) 1980-2007. The Oceanic Niño Index (ONI), used for defining ENSO is based on the running 3-m mean of ERSST.v3 SST anomaly for the Niño 3.4 region, i.e. $5^{\circ} \mathrm{N}-5^{\circ} \mathrm{S}, 120^{\circ}-170^{\circ} \mathrm{W}$, with 5 consecutive months warmer than or equal to $+0.5^{\circ}$ for El Niño and cooler than or equal to $-\mathbf{0 . 5 ^ { \circ }}$ for La Niña

\begin{tabular}{lccccccc}
\hline & TS & Cat 1 & Cat 2 & Cat 3 & Cat 4 & Cat 5 & Total \\
\hline El Niño & 28 & 12 & 3 & 9 & 7 & 0 & 59 \\
Neutral & 21 & 12 & 11 & 6 & 10 & 1 & 61 \\
La Niña & 25 & 13 & 5 & 5 & 10 & 0 & 58 \\
Total & 74 & 37 & 19 & 20 & 27 & 1 & 178 \\
\hline
\end{tabular}

Table 2b: Number of cyclones in the SWIO during the peak cyclone months (January-March) 1980-2007. ONI used for ENSO definition, same as inTable 2a

\begin{tabular}{lccccccc}
\hline & TS & Cat 1 & Cat 2 & Cat 3 & Cat 4 & Cat 5 & Total \\
\hline El Niño & 26 & 12 & 4 & 8 & 8 & 1 & 59 \\
Neutral & 21 & 12 & 12 & 10 & 12 & 3 & 70 \\
La Niña & 29 & 14 & 5 & 8 & 12 & 0 & 68 \\
Total & 76 & 38 & 21 & 26 & 32 & 4 & 197 \\
\hline
\end{tabular}


However, if higher SSTs, caused by global warming, are a reason for the increased intensity, as discussed in the introduction, then El Niño years would coincide with increased activity. Thus, it is necessary to compare TC intensity with annual SST variability.

Oceanic SSTs have increased substantially in cyclone regions during the last decades, typically by $0.2-0.5^{\circ} \mathrm{C}$ (Webster et al., 2005). Increased SSTs were suggested as a reason for the increasing numbers of ITCs, or increased activity. Then one might expect that single years of higher SSTs would also give higher activity. Figure 7 shows mean SSTs for the cyclone season in the SWIO, from 19832007. Comparing the SST anomaly (from Figure 6) indicates a correlation coefficient of about 0.1 . Thus,
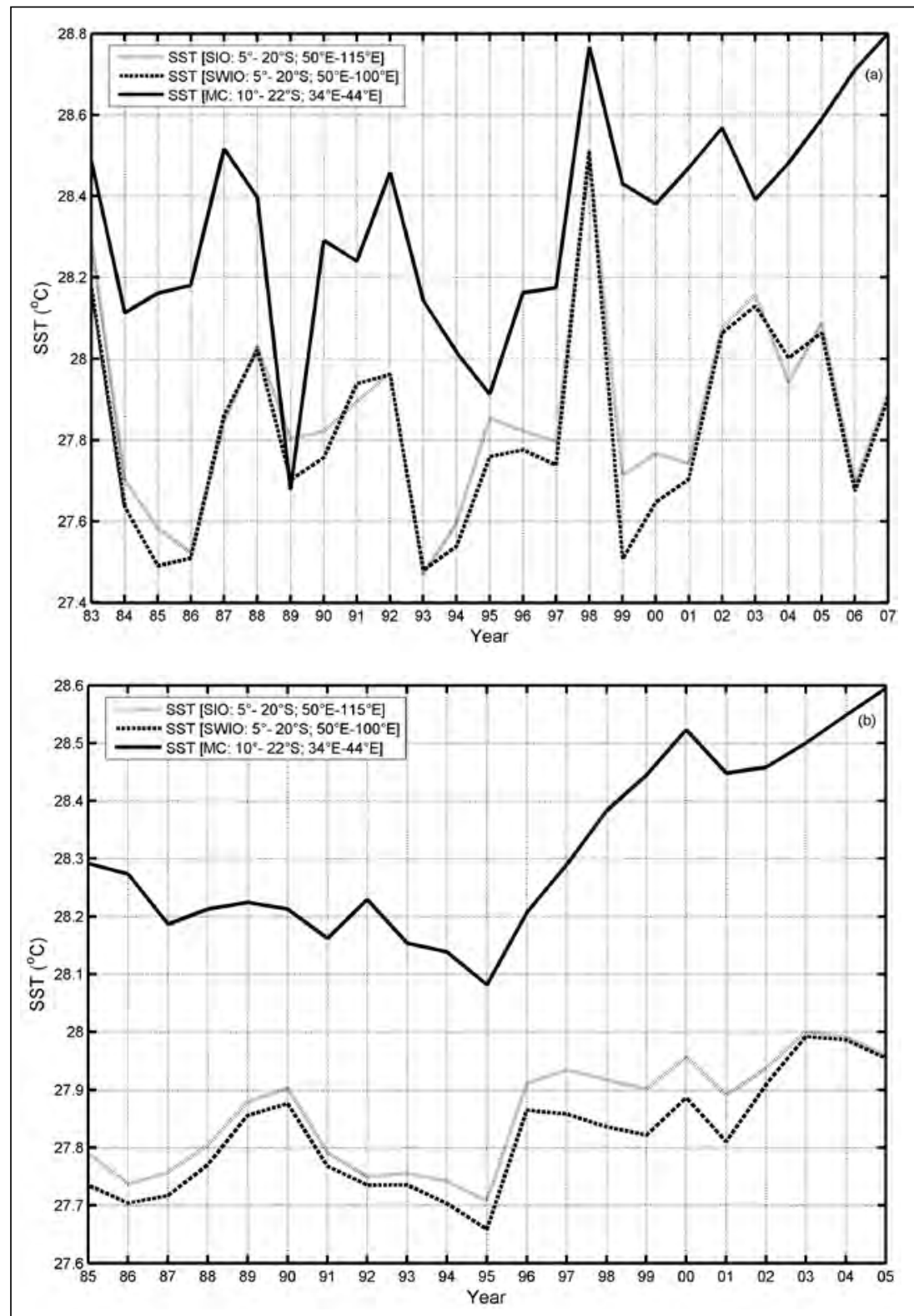

Fig. 7. Horizontal mean SST and 5-year running mean during the cyclone season (November-April) in the SWIO, the southern IO and the MC. Data based on a subset of monthly global Optimally Interpolated SST (Reynolds and Smith, 1994) 
there is no obvious correlation between SSTs and cyclone activity. Figure 7 indicates an increase of $0.12^{\circ} \mathrm{C}$ in the $\mathrm{SWIO}$ and $0.18^{\circ} \mathrm{C}$ in the $\mathrm{MC}$, between the first half of the period (1983-1994) and the second (1995-2007). When performing a least-square linear regression test, the trend in SST averaged over the MC is significantly different from zero at the $95 \%$ level while for the SWIO (E of $50^{\circ} \mathrm{E}$ ) slope there is no significance. The change is somewhat similar to that indicated by Webster et al. (2005), about $0.1^{\circ} \mathrm{C}$, from 1980 to 2003. As discussed below, this in itself seems too low a change to motivate an increase in ITCs from 36 to 56.
Figure 8a-f, shows monthly mean wind speed from November to April (1998-2005), indicating the position of the ITCZ approximately north of $20 \mathrm{~S}$ during the cyclone season. Figure $9 \mathrm{a}-\mathrm{f}$ show genesis points including cyclone tracks, for the same period and months. Figure 9a-f also shows monthly mean SSTs. Genesis during November and April is shifted towards the east and north. In February and March, genesis takes place farther south, which may be caused by sustained higher SSTs throughout March. In the MC the majority of TCs are generated in January and February. There is no formation at all in November and April, and
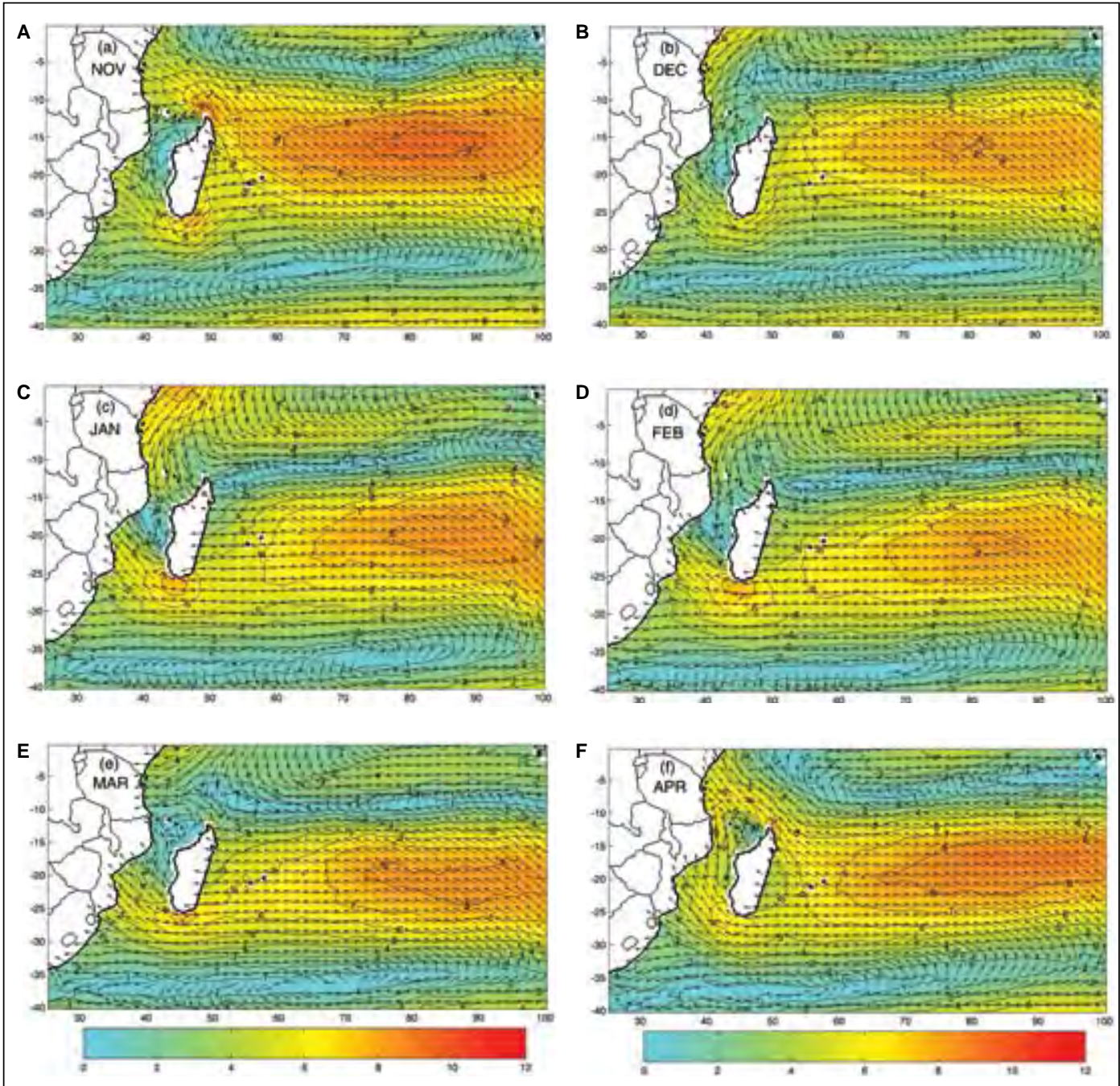

Fig. 8. Monthly mean wind velocity (2000-2006; QuikSCAT data). Surface wind convergence indicate the position of the ITCZ approximately north of $20^{\circ} \mathrm{S}$, during the cyclone season. Winds in the MC are light throughout the season 


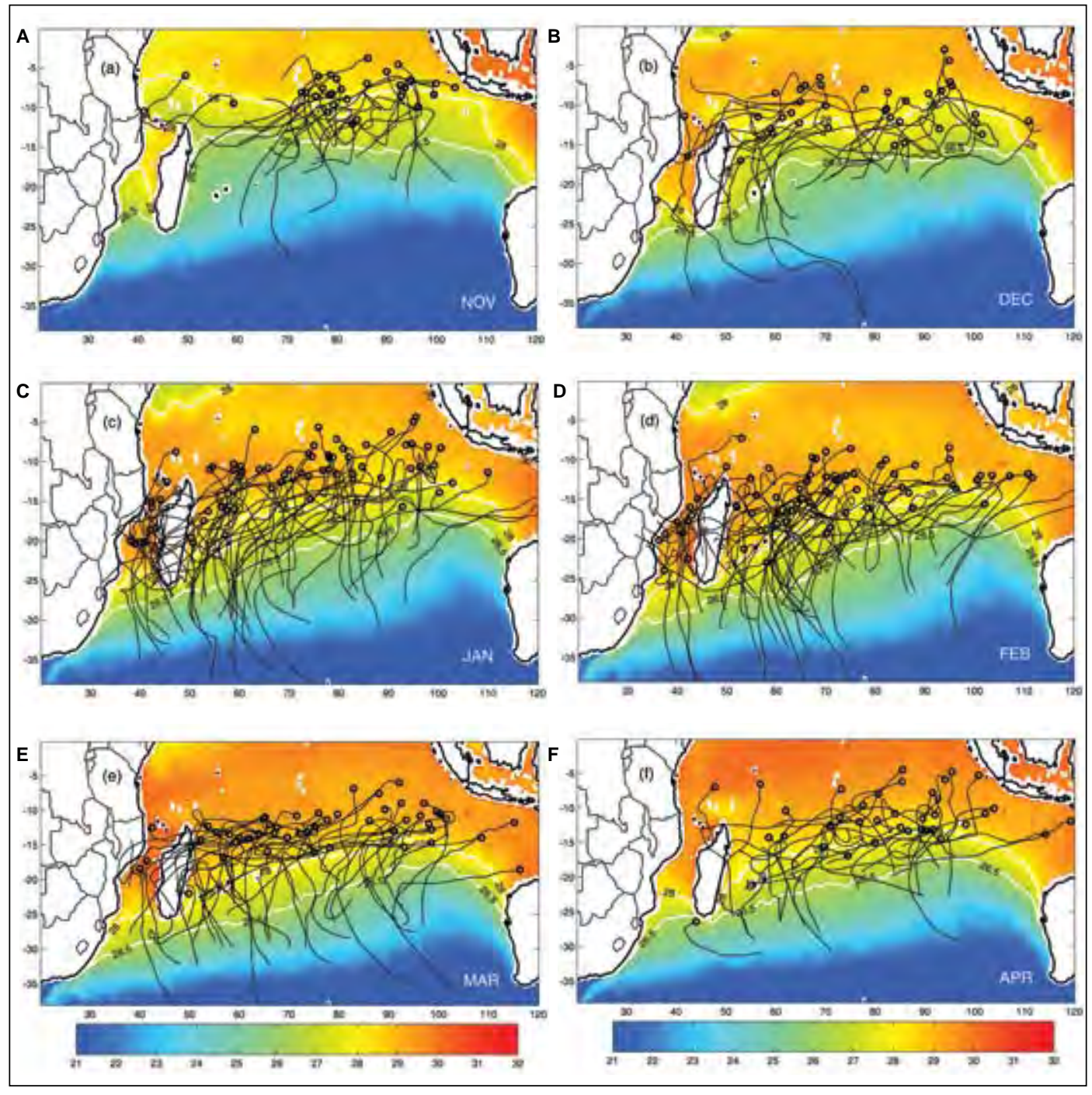

Fig. 9. Point of genesis and cyclone tracks for cyclones generated from 1998-2005. Monthly mean SSTs are indicated, with isotherms $26.5^{\circ} \mathrm{C}$ and $28^{\circ} \mathrm{C}$ highlighted

rarely in December and March, even though winds are weak and the SSTs are high (see below).

Figure 9a-f also shows that genesis is rare in areas where the mean SST is below $28^{\circ} \mathrm{C}$. Figure 10 , based on the same 1998-2005 data, shows the number of cyclones formed during each month for SST $<28^{\circ} \mathrm{C}$ and SST $>28^{\circ} \mathrm{C}$, respectively, with an average of about $28.7^{\circ} \mathrm{C}$. It corroborates what can be seen in Figure 9a-f, namely that it is only in the early and late season that genesis at SST $<28^{\circ} \mathrm{C}$ is more common. However, relating genesis to climatological SSTs is not satisfactory, because the prevailing SST at the time of genesis may be quite different. Thus SST a week prior to the storm was used to better represent the SST encountered at the genesis of each of the cyclones in the record. One cyclone only was formed in the interval from $27^{\circ}$ $27.5^{\circ} \mathrm{C}$ (Figure 11). Mean genesis SST is $29.25^{\circ} \mathrm{C}$. For cyclones generated in the MC, the mean is $29.75^{\circ} \mathrm{C}$. Thus, prevailing SSTs gives about $0.5^{\circ} \mathrm{C}$ higher mean genesis temperature than climatology SSTs. Sea surface temperature in relation to longitude indicates that cyclones in the eastern part $\left(80-100^{\circ} \mathrm{E}\right)$ are generated at lower temperatures $\left(28.25^{\circ}-29.75^{\circ} \mathrm{C}\right)$ than those in the western part $\left(50-80^{\circ} \mathrm{E}\right)$, where SSTs are $29.25^{\circ}-30.25^{\circ} \mathrm{C}$. 


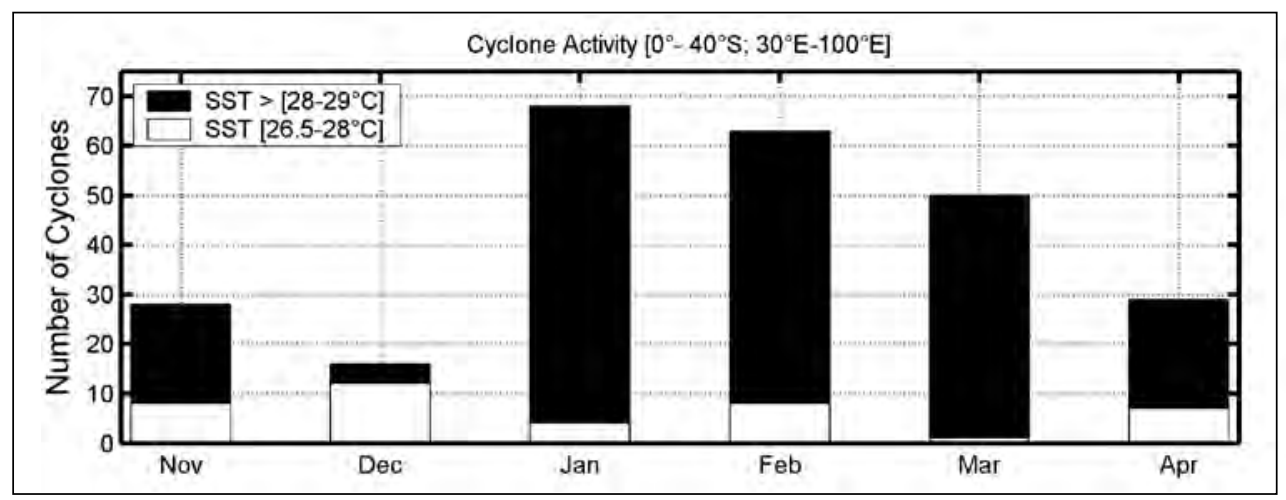

Fig. 10. Number of cyclones formed each month in the SWIO for the mean SST values defined into category like-intervals of $\mathrm{SST}<28^{\circ} \mathrm{C}$ and $\mathrm{SST}>29^{\circ} \mathrm{C}$ (same data as in Fig 9)

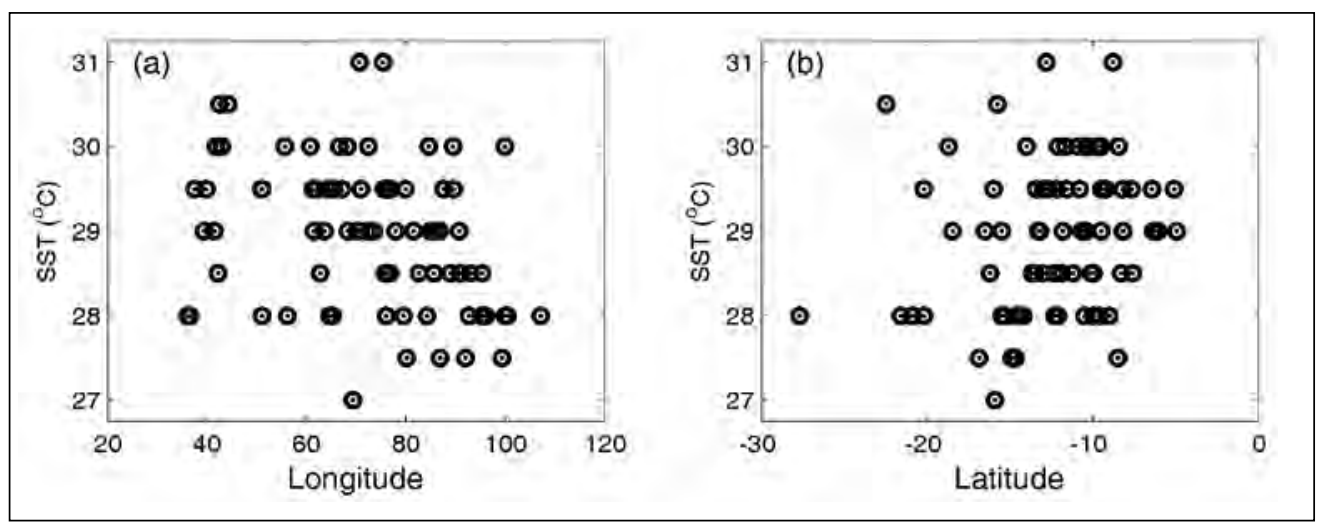

Fig. 11. Sea surface temperature and genesis location, based on cyclone track data and weekly Tropical Rainfall Measuring Mission's (TRMM) Microwave Imager (TMI) SST data (averaged for 7 days ahead of the cyclone genesis date)

Further understanding of cyclone genesis in relation to SSTs requires better information on the mixed layer heat content. This is not readily obtainable, although improved satellite data on sea level heights have been used to make indirect estimates of variations in mixed layer depth and heat content (e.g. Chambers et al. 1997; Goni and Trinanes 2003). Leipper and Volgenau (1972) have suggested that prediction of TC formation and intensification should be based on estimates of the integrated heat anomaly, from the depth of the $26^{\circ} \mathrm{C}$ isotherm to the surface;

$$
T C H P=\rho C_{P} \int_{z\left(T_{26}\right)}^{0}(T-26) \partial z
$$

where TCHP is the Tropical Cyclone Heat Potential. The SWIO has small thermocline depths, particularly compared to the North-West Pacific Ocean. According to climatological data from
WOA05, the mixed layer depths are $30-50 \mathrm{~m}$ in the open SWIO (deeper towards the south and east) and about $30 \mathrm{~m}$ in the MC. Given that a TCHP of $40 \mathrm{~kJ} / \mathrm{cm}^{2}$ might be a lower limit for sustaining a TC at normal translation speed (Leipper and Volgenau, 1972), SSTs of $29-30^{\circ} \mathrm{C}$ are required. With these figures in mind, it is obvious that an increase in the SST of $0.12^{\circ} \mathrm{C}$ (as observed in the SWIO) can hardly be considered responsible for the large increase in the number of ITCs. Such a small change in temperature would affect the TCHP by a few percent only. Or, is it possible that increased intensity counteracts increasing SSTs (and TCHPs), because strong wind mixing caused by a sufficient number of cyclones brings colder thermocline waters to the surface?

Figure 12 indicates the integrated mixing power density (proportional to the (MSW) 3 ; see Emanuel, 2005a) of all TCs in the SWIO during 1998-2005. 


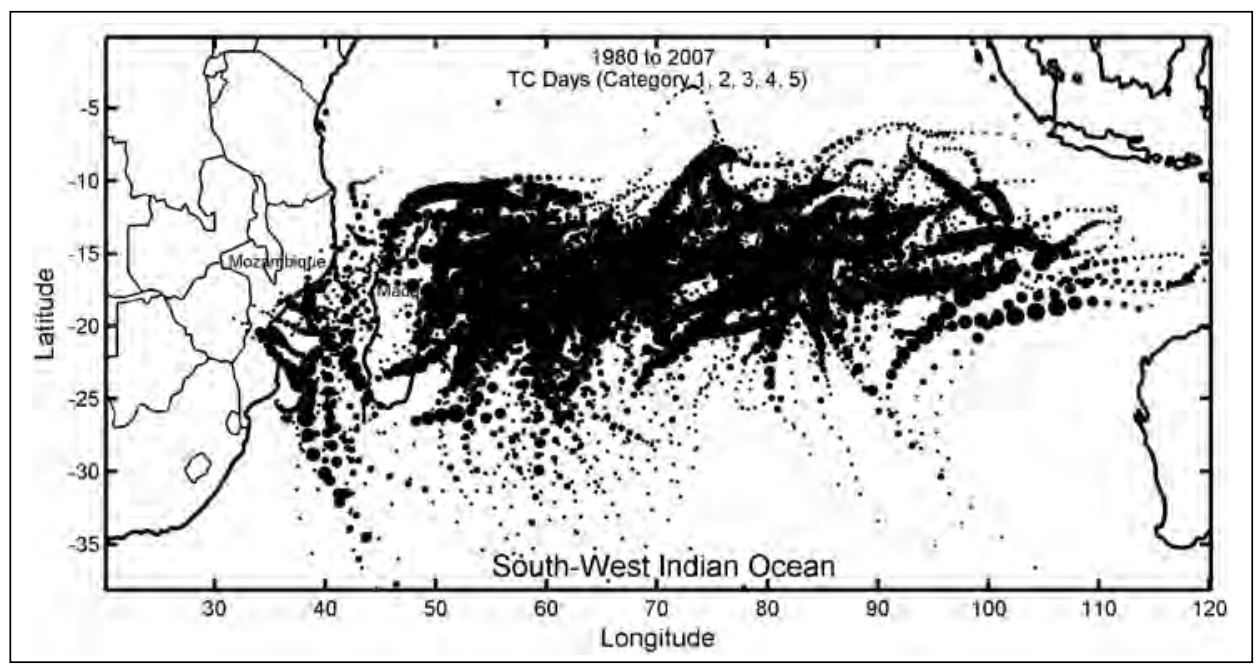

Fig. 12. Estimate of "mixing power density", integrated for all cyclones 1980-2007. The intensity along the cyclone tracks is indicated such that the size of the markers is proportional to $(\mathrm{MSW})^{3}$

As seen, the intensity (in terms of mixing power density) is largest in a narrow band from $10^{\circ}-20^{\circ} \mathrm{S}$ with a maximum between $50^{\circ}-70^{\circ} \mathrm{E}$. Mixing power density is less in the MC. It is also apparent that cyclones having their generation near to the Equator $\left(5^{\circ}-10^{\circ} \mathrm{S}\right)$ rarely develop into TCs.

\section{Genesis and track patterns in relation to ENSO}

According to Ho et al. (2006) cyclone activity increases in the southern Indian Ocean, west of $75^{\circ} \mathrm{E}$ and decreases east of $75^{\circ} \mathrm{E}$ during El Niño compared to La Niña years. Figures 13a, 13b, 14a and $14 \mathrm{~b}$ show genesis points and tracks for ITCs formed during January - March and December - February, i.e. during the peak cyclone months and the peak ENSO months, respectively, with a distinction being made between El Niño and $\mathrm{La}$ Niña years. Figure 14 also shows deviations from mean SSTs for El Niño and La Niña years.

During the peak cyclone months (Figure 13), there is a tendency for more westward generation during El Niño (warm) years compared to La Niña (cold). There are also fewer ITCs during El Niño years, but the difference is small; 17 compared to 20, for 8 and 9 seasons, respectively. Looking at the ENSO peak period (Figure 14), the situation is almost the opposite, with more ITCs in the eastern part during El Niño and fewer during La Niña.
Sixteen ITCs are generated during El Niño years and 15 during La Niña. It seems that these results reflect the general finding that ITCs are more common in the later part of the cyclone season and also appear more frequently in the eastern part of the SWIO. Figure 14 also shows that genesis in the coldest (climatology) regions is rare, both during La Niña and El Niño years.

\section{Land-falling cyclones, trends and seasonality,}

Between 1952 and 2007, 152 cyclones out of a total of 633 in the SWIO struck the coastlines of Madagascar and Mozambique (Figure 15). Of these, 88 made landfall during the period 1952-1979 and 64 during 1980-2007, indicating a surprisingly large decrease in landfall, more apparent than in the total number (330 vs 303). The recent series 1980-2007 indicates 16 landfalls in Mozambique, 9 of which were in the central part (Figures 15-16). Another 48 cyclones made landfall in Madagascar, a majority of which were on the east coast, particularly in the north-east (19). As seen from Figure 15, there are interesting differences in the statistics when comparing the earlier and the more recent period. Areas $\mathrm{E}$ and $\mathrm{F}$ were hit by many more cyclones in 1952-1979, while area B was hit by fewer. There is no obvious reason for this difference, but although data in the early series is less reliable, the difference 


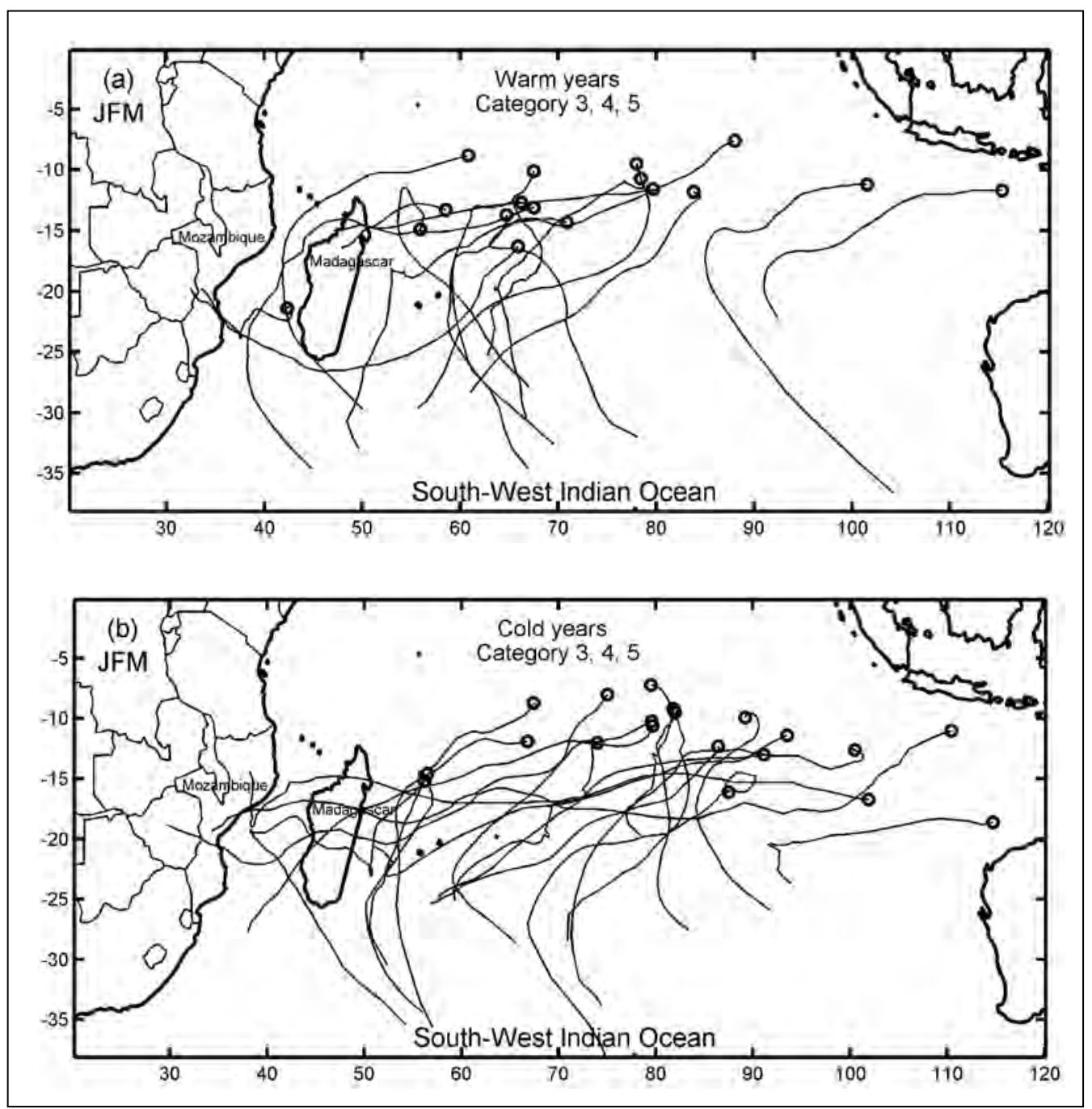

Fig. 13. January-March ITC tracks during (a) warm (El-Niño) years (1982/83, 1986/87, 1987/88, 1991/92, 1994/95, 1997/98, 2002/03, 2004/05) and (b) cold (La Niña) years (1983/84, 1984/85, 1985/86, 1988/89, 1995/96, 1998/99, 1999/00, 2000/01, 2005/06), definitions according to Ocean Niño Index (see Table 2a)

is so large that it may represent a structural change in the cyclone tracks.

Figure 17 shows the yearly number of landfalling cyclones in relation to the total number of cyclones in the SWIO. The correlation between the two series is weak. During four years, there were no landfalls at all. The genesis for land-falling cyclones is strongly displaced towards the west, as indicated in Figure 18 showing tracks for all cyclones in the SWIO, during 1952-2007. Very few cyclones generated east of $75^{\circ} \mathrm{E}$ made landfall. Given that the mean cyclone lifetime is 7-8 days and that the typical translation velocity is of the order of $200 \mathrm{~km} \mathrm{~d}^{-1}$, this origin is natural. Earlier results, indicating increasing cyclone intensity, but also that many ITCs are formed further to the east, may explain why there are fewer cyclones making landfall during the more recent period. Still, there are some exceptions, like the ITCs Hudah and Eline, both of which travelled zonally across the whole Indian Ocean in year 2000, and then made landfall both in Madagascar and in Mozambique.

It is still thought-provoking that the number of landfalls seems substantially higher in the earlier period. In the beginning of the results section, it was argued that the total number of cyclones during 


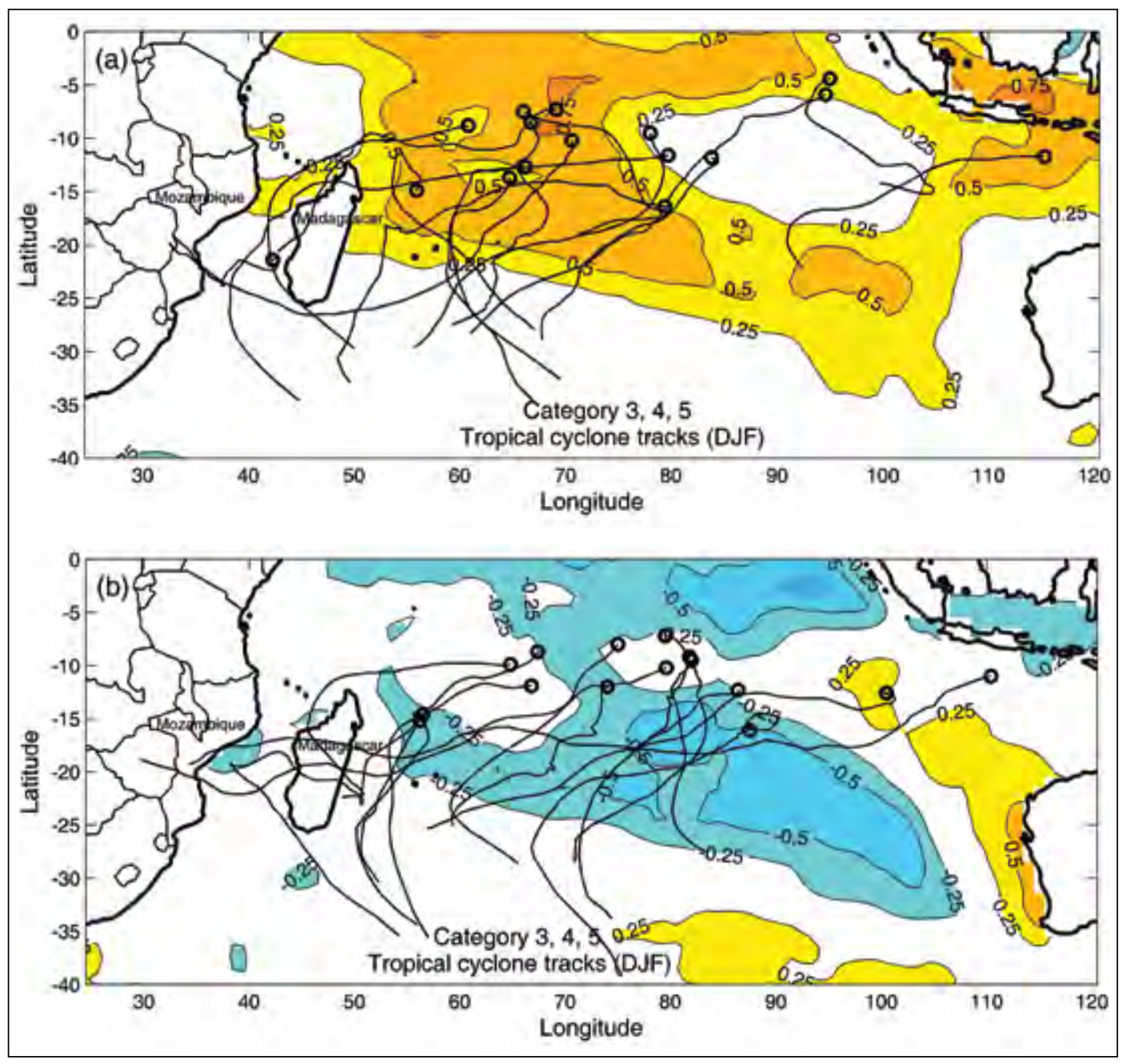

Fig. 14. December-February SST composite normalized anomalies from mean 1980-2007 with ITC tracks superimposed for the same El Niño (top panel) and La Niña (bottom) years as in Figure 13

the period 1952-1979 could be overestimated (for example such that TDs were counted as TSs, or that cyclones might have been counted more than once). However, the number of land-falling cyclones should be more readily and accurately recorded. This section is concluded by showing cyclone tracks during 1952-2007, decade-wise, in Figure 19. There were no land-falling cyclones in the 1950s and 1960s that crossed the main part of the Indian Ocean. During the 1950s cyclone tracks were shorter with an unusual genesis distribution. Apparently the records from the 1950s are questionable. However, from the 1960s and onwards, tracks and genesis seems consistent. What has changed since the 1980s is that genesis regions have been displaced towards the north-east but also, it seems, towards the south, thus the genesis region has become more widespread. However, it is noted that the record for the first decade of 2000 is incomplete, covering only seven years. It is also obvious that more cyclones were produced within the MC during the 1950s1970 s, and that several of those escaped from the channel moving southwards. Others moved southeastward and made landfall in western Madagascar (see Figure 15). Thus, there are some changes in the tracks, which may indicate large-scale atmospheric changes, presumably related to the position of the ITCZ or of the Tropical Temperate Trough. 


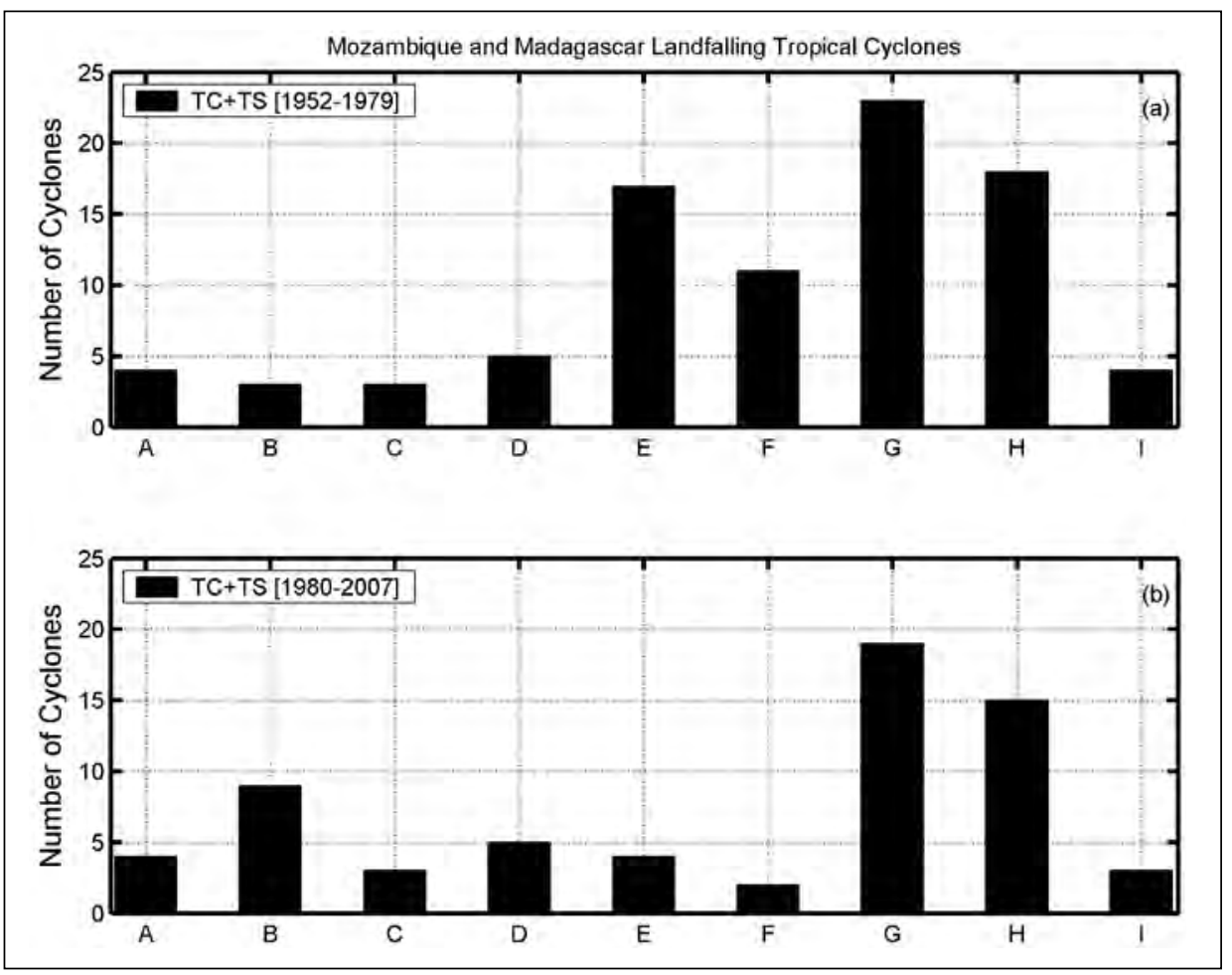

Fig. 15. Number of land-falling cyclones in Madagascar and Mozambique, region-wise according to Fig 16

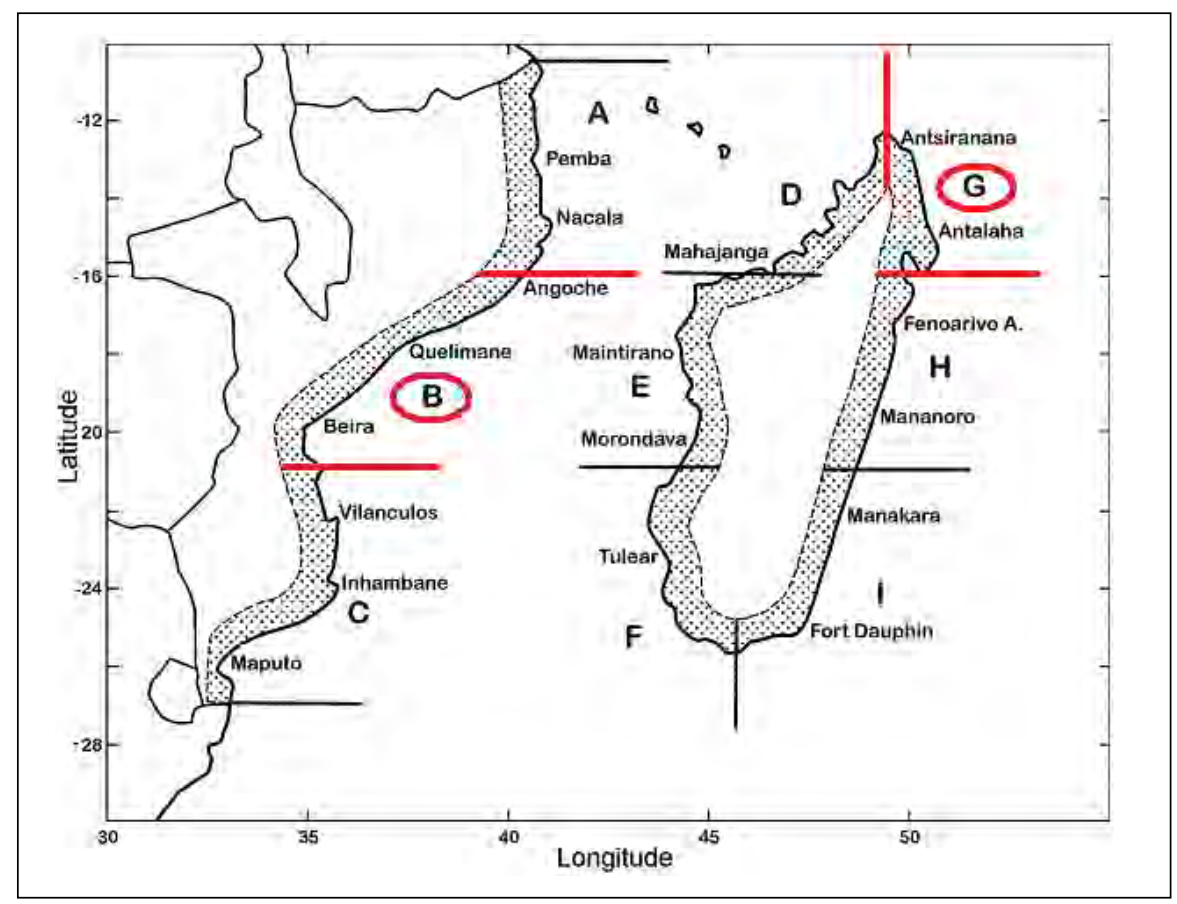

Fig. 16. Sketch of the 9 regions along the eastern and western coasts of Madagascar and the coast Mozambique where TC have their preferred landfall locations. The number of land-falling cyclones (totally 64; 1980-2007) is indicated. Red circles indicate the major areas of TC incidence 


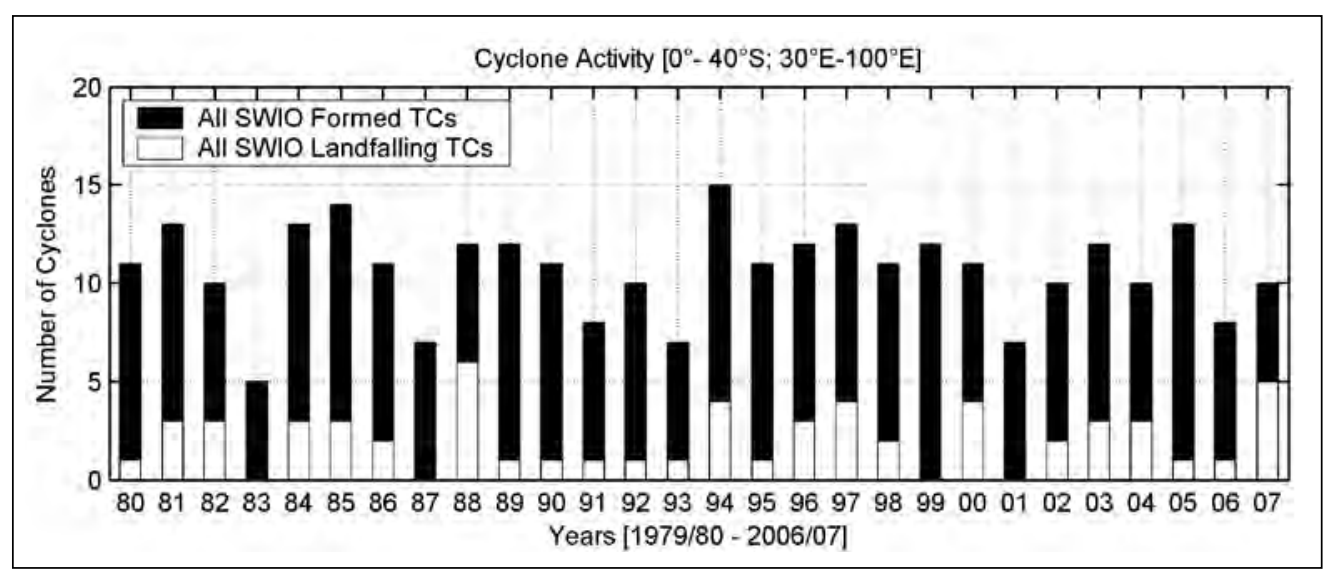

Fig. 17. Annual (November-April) number of cyclones formed in the SWIO and the number of land-falling

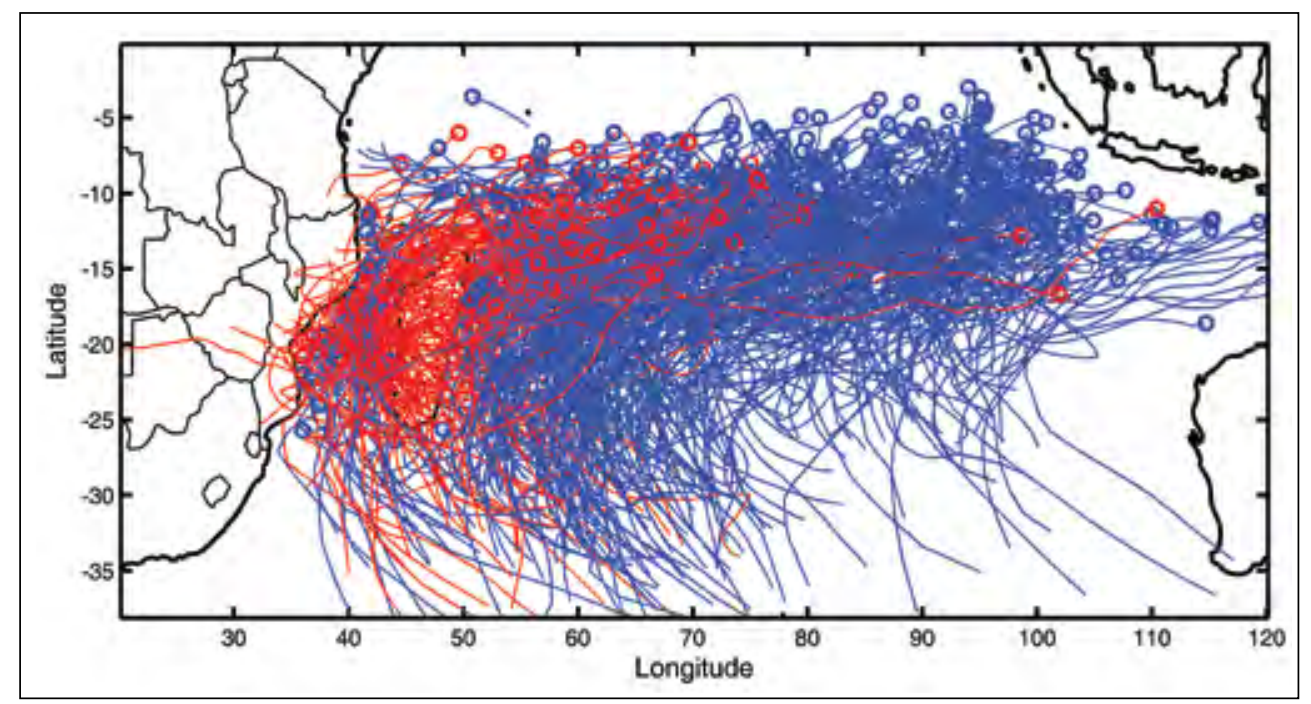

Fig. 18. Cyclone tracks (November-April) 1952-2007. Land-falling cyclone tracks are red-marked

\section{DISCUSSION AND CONCLUSIONS}

The frequency and intensity of cyclones in the SWIO during 1980-2007 (Figures 3-5) indicated overall increased activity. The number of ITCs increased from 36 to 56 when comparing the period 1980-1993 to the period 1994-2007 and the total number of cyclones increased from 138 to 155 . In the MC, the increase in ITCs was from two to seven, all of which occurred during the cyclone period, NovemberApril. The number of cyclone days also increased (Figure 6), particularly for cyclones that reached the ITC level. Similar patterns, i.e. increasing number of ITCs, have been documented for other cyclone regions of the world (e.g. Emanuel, 2005a, b; Webster et al., 2005). The total number of cyclones occurring during 1980-2007 corresponds to an annual mean frequency of $12.5,85 \%$ of which occurred during the cyclone season (November-April). In the MC, the mean frequency was $2.3 \mathrm{y}^{-1}$.

However, while there was an increase in the number of cyclones during the period 1980-2007, in the longer time series (1952-2007) there has been a decrease. In the SWIO, the decrease was from 330 (1952-1979) to 303 (1980-2007). In the MC this is even more accentuated. However, lack of intensity (MSW) data in earlier records precludes comparison on a basis of intensity. It also implies that the downward trend in the long record may be 

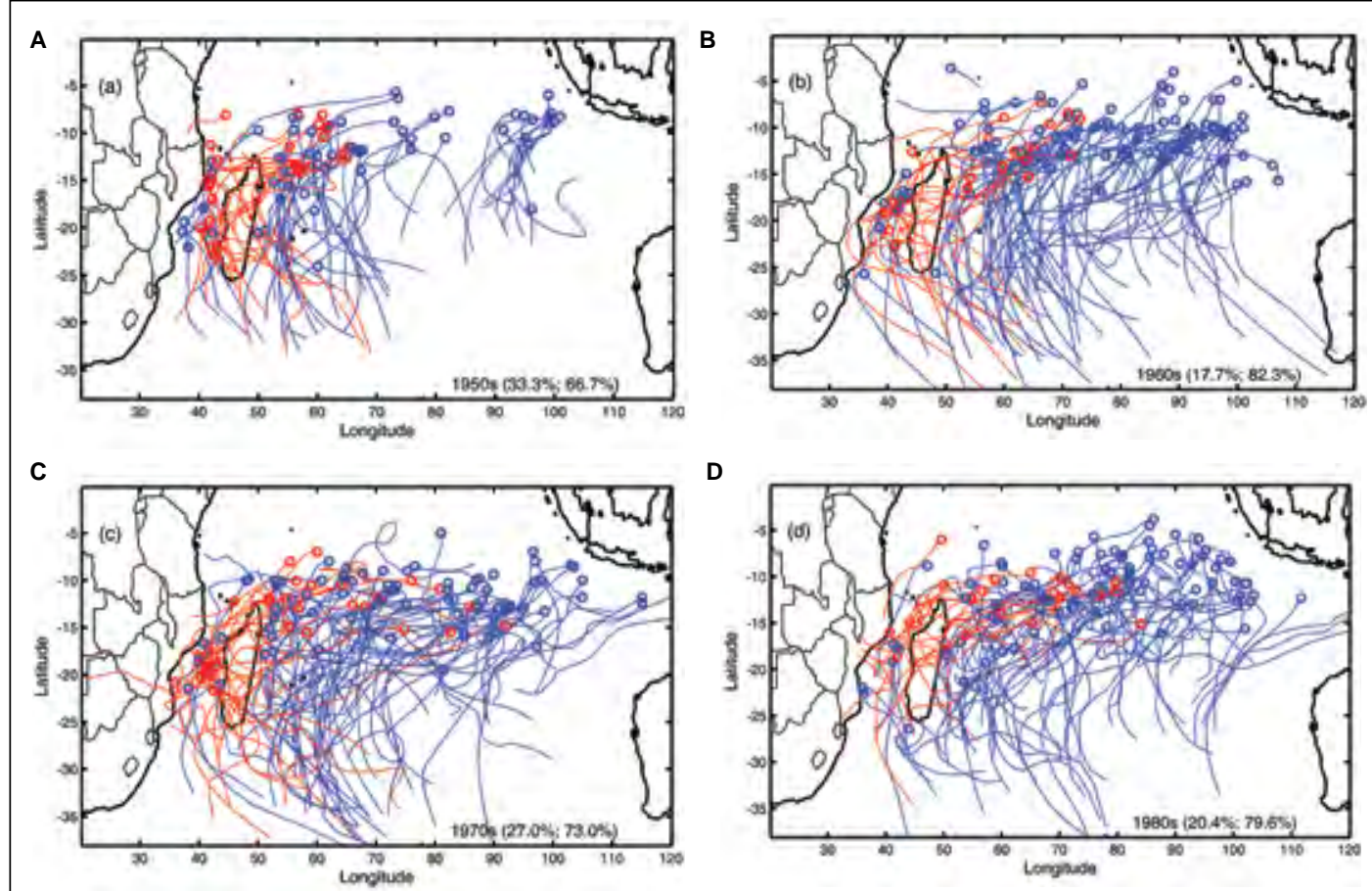

D

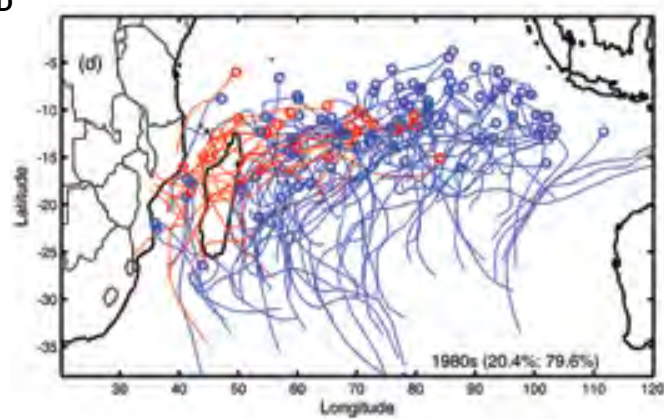

E
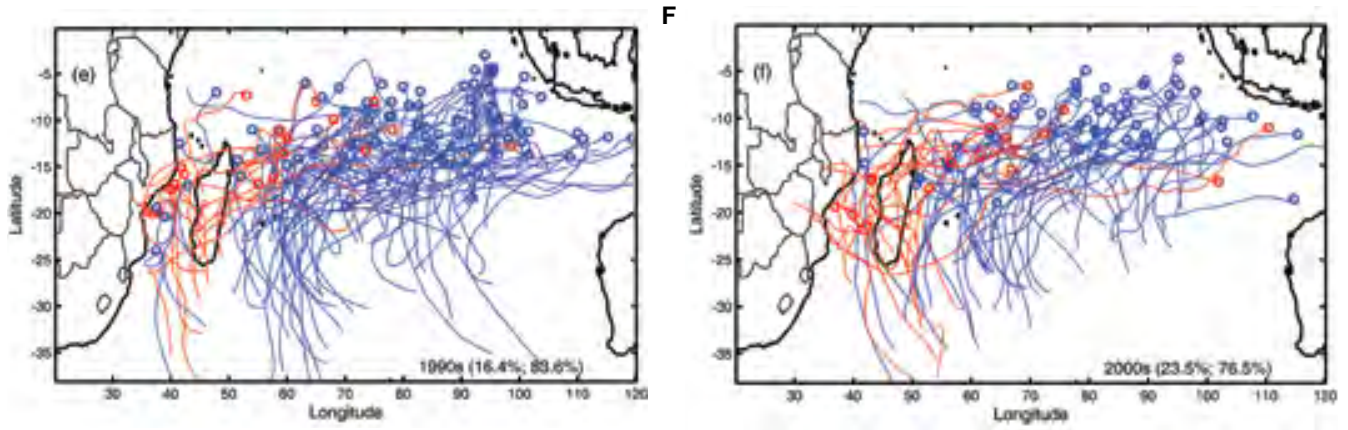

Fig. 19. Decade-wise cyclone tracks and genesis sites from the 1950 s (8 years) to the 2000 s (7 years). Land-falling tracks are red and non land-falling tracks blue

questionable, even though the decade-wise cyclone tracks shown in Figure 19 lend some support to a downward trend, particularly for cyclones in the Mozambique Channel.

The number of cyclone days (Figure 6) indicates increasing activity in recent years. As this increase was mainly due to many more ITCs, the integrated mixing power of the cyclones is also increased. Figure 12 shows that mixing power is rather evenly distributed over vast areas, although it's less strong in the MC than in the open SWIO. The figure also indicates that cyclones, developing to TCs and particularly to ITCs, are rarely formed near the
Equator. However, these features were not explored in more detail, because the rate of mixing power is poorly known for winds $>25 \mathrm{~ms}^{-1}$. The factor used here to visualise mixing power $\left(\mathrm{MSW}^{3}\right)$ may overstate its importance.

Webster et al. (2005) have stressed the considerable increase in SST values since the 1970s. Their figures for the southern Indian Ocean indicate that SSTs were about $0.3^{\circ} \mathrm{C}$ lower during the 1970s than during the 1980s-2000s. However, this was due to a rapid increase of about $0.2^{\circ} \mathrm{C}$ in the late 1970s and a smaller increase thereafter. Our data show an increase of the mean SST by $0.12^{\circ} \mathrm{C}$ 
from 1983 to 2007. Thus, while the small increase in SSTs since the 1980s has occurred at the same time as a substantial increase in cyclone activity, the more substantial increase in SST over the longer period took place while the number of cyclones decreased (Figure 3). Changes in intensity before 1980 could not be investigated, but it seems that the relationship between increasing SSTs and more intense cyclones is ambiguous This may have several reasons, some of which are discussed below.

An attempt was made to correlate inter-annual variability in the cyclone activity (Figures 9-10) with SST variability (Figure 7) and ENSO indices (Table 2a-b; Figures 13-14) without much success. Neither ENSO nor SSTs seem to affect cyclone activity (or intensity) on the annual time-scale, although occasional co-variation indicates that in combination with other atmospheric indices, related to ENSO and ITCZ variability, it may be important. A simple, but not tested, reason could be that more intense cyclones will result in deepening of the mixed layer; therefore counteracting more substantial increases of SSTs, but temperature variations some few tenths of a degree may have a relatively small impact on the TCHP.

Very few cyclones in the SWIO are formed if climatological SSTs $<28^{\circ} \mathrm{C}$ (Figures 9-10). Mean genesis SST for 80 cyclones formed during 19982005 , based on daily SSTs up to one week ahead of the cyclones, was $29.25^{\circ} \mathrm{C}$ (Figure 11). In the MC, the average was $29.75^{\circ} \mathrm{C}$. These relatively high genesis temperatures may be a result of a shallow mixed layer, typically $30 \mathrm{~m}$ in the MC and $30-50 \mathrm{~m}$ in the SWIO, with corresponding TCHPs of about $40 \mathrm{kJcm}^{-2}$. However, atmospheric conditions may have an effect as well (see below).

The number of cyclones that made landfall in Madagascar and Mozambique during the period 1952-2007 has decreased considerably, from 88 to 64. This is parallel to a decrease in the number of cyclones in the $\mathrm{MC}$, from 97 to 56, and a change in landfall patterns (Figure 19). Within the recent period (1980-2007), there is no apparent change, either in total number or in landfall, whereas there are changes in the track patterns compared to earlier decades, which may be related to large-scale atmospheric changes.

From 1980-2007, the number of land-falling cyclones in Mozambique was 16, a majority of which made landfall in the central region of the country (Figures 15-16). Another 48 cyclones made landfall in Madagascar, 37 of which on the eastern side, mainly to the north-east. Five intense tropical cyclones made landfall on the Mozambique coast, while 19 hit the coasts of Madagascar. However, there does not seem to be any correlation between frequency in general and that of land-falling cyclones (Figure 17).

It has been suggested that the increased number of ITCs is due to larger mixed layer heat content and/or higher SSTs (Vitart et al., 2003). However, the maximum frequency of ITCs in March and of TS in February points towards the opposite, as heat content and SSTs are lower in March than in February. Also, the number of ITCs is higher during cold La Niña years compared to warm El Niño years (Figures 13-14). Several authors (e.g. Gray, 1984; Bove et al., 1998; Jury, 1993) have argued that suppressed activity of ITCs may be attributed to a stronger vertical westerly shear and reduced upper layer, anti-cyclonic vorticity. Such conditions, which are typical for El Niño years, may thus hinder genesis and/or hinder a cyclone from intensifying to become an ITC.

\section{REFERENCES}

Anthes, R. A., (1982). Tropical cyclones, their evolution, structure and effects, Met Mon 19, 41, 208 pp.

Bessafi, M. and Wheeler, M. C., (2006). Modulation of south Indian Ocean tropical cyclone by the Madden-Julian oscillation and convectively-coupled equatorial waves. Monthly Weather Review, 134, 638-656

Bove, M.C., Elsner, J.B., Landsea, C.W., Niu, X. and O'Brien, J.J., (1998). Effects of El Niño on U.S. Landfalling Hurricanes. Revisited. Bull. Amer. Meteor. Soc., 79, 2477-2482

Cardillo, G., (2007). MyRegression: a simple function on LS linear regression with many informative outputs. (http://www.mathworks.com/matlabcentral/ fileexchange /15473).

Chambers, D. P., Tapley, B. D. and Stewart, R. H., (1997). Long-period ocean heat storage rates and basin-scale heat fluxes from TOPEX. Journal of Geophysical Research, 102, 10,525-10,533.

deMaria, M. and Kaplan, J., (1994). A Statistical Hurricane Intensity Prediction Scheme (SHIPS) for the Atlantic Basin. Weather Forecast, 9, 209-220.

Dvorak, V. F., (1984). Tropical cyclone intensity analysis using satellite data. NOAA Technical Report, NESDIS 11, 47 pp. 
Emanuel, K. A., (2003). Tropical Cyclones. Annual Review of Earth and Planetary Science, 31, 75-104, doi: 10.1146/annurev.earth.31.100901.141259.

Emanuel, K. A., (2005a). Increasing destructiveness of tropical cyclones over the past 30 years. Nature, 436, 686-688.

Emanuel, K. A., (2005b). The dependence of hurricane intensity on climate. Nature 326, 483-485.

Fink, H. A. and Speth, P., (1998). Tropical cyclones. Naturwissenschaften, 85, 482-493.

Goni, G., and Trinanes, J., (2003). Ocean thermal structure monitoring could aid in the intensity forecast of tropical cyclones, EOS, Transactions of the American Geophysical Union, 84, 51.

Gray, W. M., (1975). Tropical Cyclone Genesis. Colorado State University, Department of Atmospheric Science, Paper No. 234, 121 pp.

Gray, W. M., (1984). Atlantic seasonal hurricane frequency. Part I: El Nino and $30 \mathrm{mb}$ quasi-biennal oscillation influences. Monthly Weather Review, 112, 1649-1668.

Henderson-Sellers, Zhang, H., Berz, G., Emanuel, K., Gray, W., Landsea, C., Holland, G., Lighthill, J., Shieh, S.-L., and Webster, P., (1998). Tropical cyclones and global climate change: A post IPCC assessment, Bulletin of the American Meteorological Society, 79, 19-38.

Ho, C.-H., Kim, J.-H., Jeong, J.-H., Kim, H.-S. and Chen, D., (2006). Variation of tropical cyclone activity in the South Indian Ocean: El Niño-Southern Oscillation and Madden-Julian Oscillation effects. Journal of Geophysical Research, 111, D22101, doi:10.1029/2006JD007289.

Holland, G. J. and Webster, P. J., (2007). Heightened tropical cyclone activity in the North Atlantic: natural variability or climate trend? Philosophical Transactions of the Royal Society A, doi:10.1098/ rsta. 2007. 2083.

Jury, M. R., (1993). A preliminary study of climatological associations and characteristics of tropical cyclones in the SW Indian Ocean, Meteorology and Atmospheric Physics, 51, 101-115.

Kalnay, E., Kanamistsu, M., Kistler, R., Collins, W., Deaven, D., Gandin, L., Iredell, M., Saha, S., White, G., Woolen, J., Zhu, Y., Leetmaa, A., Reynolds, B., Chelliah, M., Ebisuzaki, W., Higgins, W., Janowiak, J., Mo, K. C., Ropelewski, C., Wang, Jenne, R. and Joseph. D., (1996). The NCEP/NCAR 40-year reanalysis. Bulletin of the American Meteorological Society, 77, 437-471.

Knapp, K. R. and Kossin, J.P., (2007). New global tropical cyclone data set from ISCCP B1 geostationary satellite data, Journal of Applied Remote Sensing, 1,013505 .
Kuleshov, Y. and de Hoedt, G., (2003). Tropical cyclone activity in the Southern Hemisphere. Bulletin of the Australian Meteorological Society, 16, 135-137.

Klinman M.G, Reason C. J., (2008). On the peculiar storm track of TC Favio during the 2006-2007 Southwest Indian Ocean tropical cyclone season and relationships to ENSO. Meteorology and Atmospheric Physics 100(1-4): 233.

Kuleshov, Y., Qi, L., Fawcett, R. and Jones, D., (2008). On tropical cyclone activity in the Southern Hemisphere: Trends and the ENSO connection, Geophysical Research Letters, 35, L14S08, doi:10.1029/2007GL032983.

Landman, W. A., Seth, A. and Camargo, S. J., (2005). The effect of regional climate model domain choice on the simulation of tropical cyclone-like vortices in the south-western Indian Ocean. Journal of Climate, 18, 1263-1274.

Landsea, C. W., (2007). Counting Atlantic tropical cyclones back to 1900. EOS, Trasactions of the American Geophysical Union, 88, 197-208.

Landsea, C. W., Pielke, R. A., Mestas-Nuñez, A. M. and Knaff, J .A., (1999). Atlantic basin hurricanes. Indices of climatic changes. Climate Change, $\mathbf{4 2}$, 89-129.

Landsea, C. W., Harper, B. A., Hoarau, K. and Knaff, J. A., (2006). Can we detect trends in extreme tropical cyclones? Science, 313, 452-454.

Leipper, D. F., and Volgenau, D., (1972). Hurricane heat potential of the Gulf of Mexico. Journal of Physical Oceanography, 2, 218-224.

Madden, R. A. and Julian, P. R., (1994). Observations of the 40-50 day tropical oscillation - A review. Monthly Weather Review, 122, 814-837.

McBride, J. L., (1995). Tropical cyclone formation. In: Elsberry, R. L. (ed.), Global perspectives on tropical cyclones. World Meteorological Organization, Geneva.

Neumann, C. J., (1993). Global Overview. In: Holland, G. J. (ed.), Global Guide to Tropical Cyclone Forecasting, World Meteorological Organization, Geneva, WMO/TC-No. 560, Report No. TCP-31,

Palmén, E., (1948). On the formation and structure of tropical hurricanes. Geophysica, 3, 26-38.

Pielke, R. A. Jr., (2005). Are there trends in hurricane destruction? Nature, 438. E11

Pielke, R. A. and Landsea, C. W. (1999). La Niña, El Niño, and Atlantic hurricane damages in the United States. Bulletin of the American Meteorological Society, 80, 2027-2033.

Reason, C. J. C. and Keibel, A., (2004). Tropical Cyclone Eline and its unusual penetration and impacts over the southern Africa mainland. Weather and Forecasting, 19, 789-805. 
Reynolds, R. W. and Smith, T. M., (1994). Improved global sea surface temperature analyses. J. Climate, 7, 929-948.

Saffir,H. S., (1974). Saffir-Simpson Scale for Hurricanes. Herbert S. Saffir Consulting Engineers, Coral Gables, Florida, pp. 21-23.

Sen,P.K., (1968). Estimates of the regression coefficient based on Kendall's tau. Journal of the American Statistical Association, 63, 1379-1389.

Simpson, R.H. and Riehl,H., (1981). The hurricane and its impact. Basil Blackwell, Oxford.

Sobel, A.H. and Maloney, E.D., (2000) Effect of Enso and the MJO on western north Pacific tropical cyclones. Geophysical Research Letters, 27, 17391742

Trenberth, K. E., (2005). Uncertainty in hurricanes and global warming, Science, 308, 1753-1754.

Vitart, F., Anderson, J. L. and Stockdale, T., (2003). Seasonal forecasting of tropical cyclone landfall over Mozambique. Journal of Climate, 16, 3932-3945.

Webster, P. J., Holland, G. J., Curry, J. A. and Chang, H.-R., (2005). Changes in tropical cyclone number, duration, and intensity in a warming environment. Science 309, 1844-1846, doi:10.1126/ science. 1116448.

Xie, S.-P., Annamalai, H., Schott, F. A. and McCreary, J. P., (2002). Structure and mechanisms of south Indian Ocean climate variability. Journal of Climate, 15, 864-878.

$\mathrm{Xu}$, J.-S., (1992). On the relationship between the stratospheric quasi-biennial oscillation and the tropospheric southern oscillation. Journal of Atmospheric Science, 49, 725-734.

Yue, S., Pilon, P. and Cavadias, G., (2002). Power of the Mann-Kendall and Spearman's rho tests for detecting monotonic trends in hydrological series. Journal of Hydrology, 259, 254-271.

Zhang, Y., Rossow, W. B., Lacis, A. A., Oinas, V. and Mishchenko, M. I., (2004). Calculation of radiative fluxes from the surface to top of atmosphere based on ISCCP and other global data sets: Refinements of the radiative transfer model and the input data. Journal of Geophysical Research, 109, D1910, doi:10.1029/2003JD00447. 
